OPEN ACCESS

Edited by:

Yue Liu,

Xiyuan Hospital, China

Reviewed by:

Ali H. Eid,

American University of Beirut, Lebanon

Yanfei Liu,

Beijing University of Chinese Medicine, China

${ }^{*}$ Correspondence:

Gjumrakch Aliev

aliev03@gmail.com;

cobalt55@gallyinternational.com

Specialty section:

This article was submitted to

Ethnopharmacology,

a section of the journal

Frontiers in Pharmacology

Received: 06 December 2019

Accepted: 17 March 2020

Published: 08 April 2020

Citation:

Kirichenko TV, Sukhorukov VN,

Markin AM, Nikiforov NG, Liu P-Y, Sobenin IA, Tarasov W, Orekhov AN and Aliev G (2020) Medicinal Plants as a Potential and Successful Treatment

Option in the Context of Atherosclerosis.

Front. Pharmacol. 11:403. doi: 10.3389/fphar.2020.00403

\section{Medicinal Plants as a Potential and Successful Treatment Option in the Context of Atherosclerosis}

\author{
Tatiana V. Kirichenko ${ }^{1,2,3}$, Vasily N. Sukhorukov ${ }^{1,2,3}$, Alexander M. Markin ${ }^{1}$, \\ Nikita G. Nikiforov ${ }^{2,3}$, Ping-Yen Liu ${ }^{4,5}$, Igor A. Sobenin ${ }^{1,3}$, Vadim V. Tarasov ${ }^{6}$, \\ Alexander N. Orekhov ${ }^{1,2}$ and Gjumrakch Aliev ${ }^{6,7,8,9^{*}}$
}

${ }^{1}$ Laboratory of Infection Pathology and Molecular Microecology, Research Institute of Human Morphology, Moscow, Russia, 2 Laboratory of Angiopathology, Institute of General Pathology and Pathophysiology, Moscow, Russia, ${ }^{3}$ Laboratory of Medical Genetics, National Medical Research Center of Cardiology, Moscow, Russia, ${ }^{4}$ Institute of Clinical Medicine, College of Medicine, National Cheng Kung University, Tainan, Taiwan, ${ }^{5}$ Division of Cardiology, College of Medicine, National Cheng Kung University Hospital, Tainan, Taiwan, 6 Sechenov First Moscow State Medical University (Sechenov University), Moscow, Russia, ${ }^{7}$ Institute of Physiologically Active Compounds, Russian Academy of Sciences, Chernogolovka, Russia, ${ }^{8}$ GALLY International Research Institute, San Antonio, TX, United States, ${ }^{9}$ Laboratory of Molecular Pathology, Research Institute of Human Morphology, Moscow, Russia

Atherosclerosis is a chronic multifactorial disease characterized by mainly changes of blood lipids profile and inflammation in vessel wall. The cardiovascular disease based on atherosclerosis is currently the leading cause of mortality in developed countries. Therefore, timely prevention and therapy of atherosclerosis are able to reduce the risk of the development of its clinical manifestations. Anti-atherosclerotic activity of medicinal plants mainly appears in their multiple effects such as anti-inflammatory, antioxidant, antiatherogenic, hypotensive, lipid-lowering, anti-thrombotic. Moreover, most of medicinal plants are characterized by their pleiotropic anti-atherosclerotic action. In addition, the medicinal plants-derived pharmacological substances and/or compounds are characterized by relative safety and fewer side effects that allows considering them as one of potential anti-atherosclerotic effective agents. The direct anti-atherosclerotic effect of some medicinal plants was confirmed in clinical trials of carotid Intima-media thickness (IMT) progression during long-term medication with medicinal plants. This review attempted to determine the current status of the databases PubMed and Scopus (until November, 2019) to investigate the medicinal plants possessing anti-atherosclerotic activity in experimental and clinical studies.

Keywords: medicinal plants, atherosclerosis, cardiovascular risk, anti-atherosclerotic mechanisms, carotid IMT

\footnotetext{
Abbreviations: LDL, low-density lipoproteins; HDL, high-density lipoproteins; TC, total cholesterol; Tg, triglycerides; hsCRP, high-sensitive C-reactive protein; cIMT, intima-media thickness of carotid arteries; VCAM-1, Vascular cell adhesion molecule-1; ICAM-1, Intercellular adhesion molecule-1; TNF, tumor-necrosis factor; IL, interleukin; HLA-DR - human leukocyte antigen - DR isotype; HUVECs, human umbilical vein endothelial cells; NO, nitric oxide; HMG-CoA, 3-hydroxy-3methyl-glutaryl coenzyme A reductase; SREBP-1c, sterol regulatory element binding protein-1c (); COX-2, cyclooxygenase-2; BMI, body mass index; T2D, type 2 diabetes mellitus; DBP, diastolic blood pressure; SBP, systolic blood pressure; ACAT, AcylCoA-cholesterol-acyltransferase); PPAR, peroxisome proliferator-activated receptors.
} 


\section{INTRODUCTION}

Atherosclerosis is a chronic multifactorial disease characterized by dyslipidemia and inflammation. Nowadays it is one of the key reasons of cardiovascular disease that is currently the leading cause of mortality in developed countries (Libby et al., 2011; Fredman and Spite, 2013). Atherosclerosis develops in the human arteries for many years, and remains asymptomatic for a long time. Patients very often learn about the presence of atherosclerotic lesions when they seek medical attention because of the development of cardiovascular disease, that is a complication of the atherosclerotic process. However, initial atherosclerotic lesions can be identified at the subclinical stage by modern diagnostic methods, which make it possible to start prevention timely. Antiatherosclerotic therapy is very important for the prevention of diseases of this group and their complications. Non-drug methods of prevention exist and apply. They are based on the prevention of the development of cardiovascular disease by changing lifestyle, keeping a diet, and administration of courses of medicinal plants and natural products that possess anti-atherosclerotic properties (Pogosova et al., 2017).

In general, atherosclerosis can be also described as a type of immunological disorder, in which immune cells are activated along the inflammatory pathway and migrate into the vascular intima. After that, atherosclerotic lesion may develop in this place (Frostegard, 2013). Recent data indicate that the prevailing beliefs about the decisive role of high cholesterol in the development of atherosclerosis are not entirely correct. High blood cholesterol does not always clearly correlate with the presence of atherosclerotic lesions in arterial wall and complications of atherosclerosis process (Orekhov and Ivanova, 2017).

Currently, a strategy for the correction of lipid metabolism disorders is widely used around the world to treat atherosclerosis. But at the same time, researchers are developing methods to counteract inflammatory processes in the vessel wall at cellular level. The viability of these methods is indicated by the latest data from studies of the pathogenesis of atherosclerotic lesions. This process begins in the intima layer of large and medium arteries, especially in places of bifurcation. Vascular wall of such areas experiences increased stress due to the turbulent effects of blood flow. This causes damage to the cells of endothelial layer of intima, resulting in attracting of immune cells due to the production of adhesion molecules. (Koch and Zernecke, 2014). At the same time, low-density lipoproteins (LDL) undergo modification (Nikifirov et al., 2017; Alipov et al., 2017) and acquire the ability to penetrate and accumulate at the subendothelial level of the arterial wall. There they can additionally undergo oxidation, turning into oxidized LDL. Monocytes attracted by endothelial cells in the intimal space differentiate into macrophages and absorb oxidized LDL. However, in the event of a violation of the processes of cholesterol metabolism in macrophages, they are transformed into foam cells (Pirillo et al., 2013; Lopes-Virella and Virella, 2013; Witztum and Lichtman, 2014; Akhter et al., 2016; Tabas and Lichtman, 2017).
Thus, the activation of cascades of immune and inflammatory reactions is crucial for the progression of atherosclerotic lesions. In attempt to influence these processes, several new strategies for the treatment of atherosclerosis, based on the use of various therapeutic agents to inhibit the pro-inflammatory activation of immune cells or stimulate signals to the anti-inflammatory activity of body systems, have recently appeared. They can be used as an addition to conventional methods of treating cardiovascular diseases based on the use of lipid-lowering preparations (Li et al., 2017; Chistiakov et al., 2018). However, the most common preparations used for anti-atherosclerotic therapy are currently statins since they possess multiple antiatherosclerotic properties (Davignon, 2012; Tian et al., 2012; Oesterle et al., 2017), but their prescription is still limited because of prolonged administration of preparations of this group leads to a risk of undesirable side effects so statins are traditionally prescribed to patients with hypercholesterolemia (Stroes et al., 2015; Beckett et al., 2015).

Nowadays, there are no preparations that can be used for long-term prevention and treatment of atherosclerosis without the risk of developing pronounced side effects. This leads to the extremely high relevance of the study and use of medicinal plants for long-term anti-atherosclerotic therapy. Actually, the medical properties of various plants have been known since ancient times. A large number of herbal preparations are capable of exerting inhibitory effects in pathological immune reactions, and some of them have traditionally been used for the modulation of atherosclerosis progression. It can be explained by their relative safety, fewer side effects, and, in a sense, their greater effectiveness. Since cytokines are the main mediators in all types of inflammation, that is a significant factor at all phases of the atherosclerosis progression, the studies of the use of medicinal plants for modulation of cytokines production are very relevant in the field of atherosclerosis medication (Ramji and Davies, 2015; Fatkhullina et al., 2016). In addition, medicinal plants are widely used for the correction of conventional risk factors of atherosclerosis such as hyperlipidemia, hypertension, and etc. (Tariq et al., 2016; Chukwuma et al., 2019). The variety of clinical trials' results of various research groups studying medicinal plants can be partially explained by the multiple mechanisms of action on various cardiovascular risk factors. In addition, some visualization methods give encouraging results. For example, evaluation of the carotid intima-media thickness (CIMT) indicator (intima-media thickness of the carotid arteries) using ultrasound investigation can quantify the progression of atherosclerotic lesions and evaluate the direct effect of these preparations on atherosclerosis (Bots et al., 2016; Katakami et al., 2019).

This review reflects current views on how medicinal plants are used to reduce the risk of atherosclerosis development, their direct or indirect anti-atherosclerotic effects. English scientific literature was searched using electronic databases PubMed and Scopus by keywords "medicinal plants", "natural products", "atherosclerosis", "intima-media thickness", "cardiovascular risk", "clinical trial" in different combinations until November, 
2019, with first focus on medicinal plants with proven direct antiatherosclerotic activity in patients with carotid atherosclerosis and natural products possessing cardioprotective effects in clinical trials, and further their anti-atherosclerotic mechanisms of action were reviewed. We will focus on medicinal plants and the products created on their base, used in modern practice meeting the principles of evidence-based medicine.

\section{POSSIBLE ANTI-ATHEROSCLEROTIC MECHANISMS OF MEDICINAL PLANTS}

Atherosclerosis is a multifactorial process, and despite the great progress in understanding the mechanisms of the development of atherosclerotic lesions in the last decades, the pathogenesis of atherosclerosis is the subject of study by a large circle of scientists around the world. Nevertheless, the key points of the pathogenesis of atherosclerosis are known, and the possible pathogenetic mechanisms of the anti-atherosclerotic effects of medicinal plants are being studied in cell cultures, animal models, and human studies. Figure 1 summarizes plausible effects of medicinal plants reviewed in this article, on different stages of atherosclerosis development. The effects of the most promising natural anti-atherosclerotic agents are noteworthy.

Numerous studies describe the contribution of proinflammatory cytokines to the formation of atherosclerotic lesions in arterial wall. Evidence from these studies underlies the potential use of anti-cytokine therapy that can become a promising direction for the correction of changes at early stages of the atherosclerosis development. Thanks to recent studies, it was found that components of a large number of medicinal plants are capable of modulating the pathways of the inflammatory response. Many of these natural products have anti-cytokine mechanism of action, and most of them do not possess pronounced side effects and can be used for long-term prevention and treatment of atherosclerosis. In particular, herbal preparation Inflaminat, mixture of black elder (Sambucus nigra L.), violet tricolor (Viola tricolor L.), and calendula (Calendula officinalis L.), significantly inhibits the expression of inflammatory cytokines via inhibiting IL-6 and TNF- $\alpha$ expression and alleviates serum atherogenic activities via unknown mechanism in ex vivo model (Kirichenko et al., 2016).

There are some beneficial data of multiple anti-inflammatory and anti-atherosclerotic effects of glabridin, a flavonoid isolated

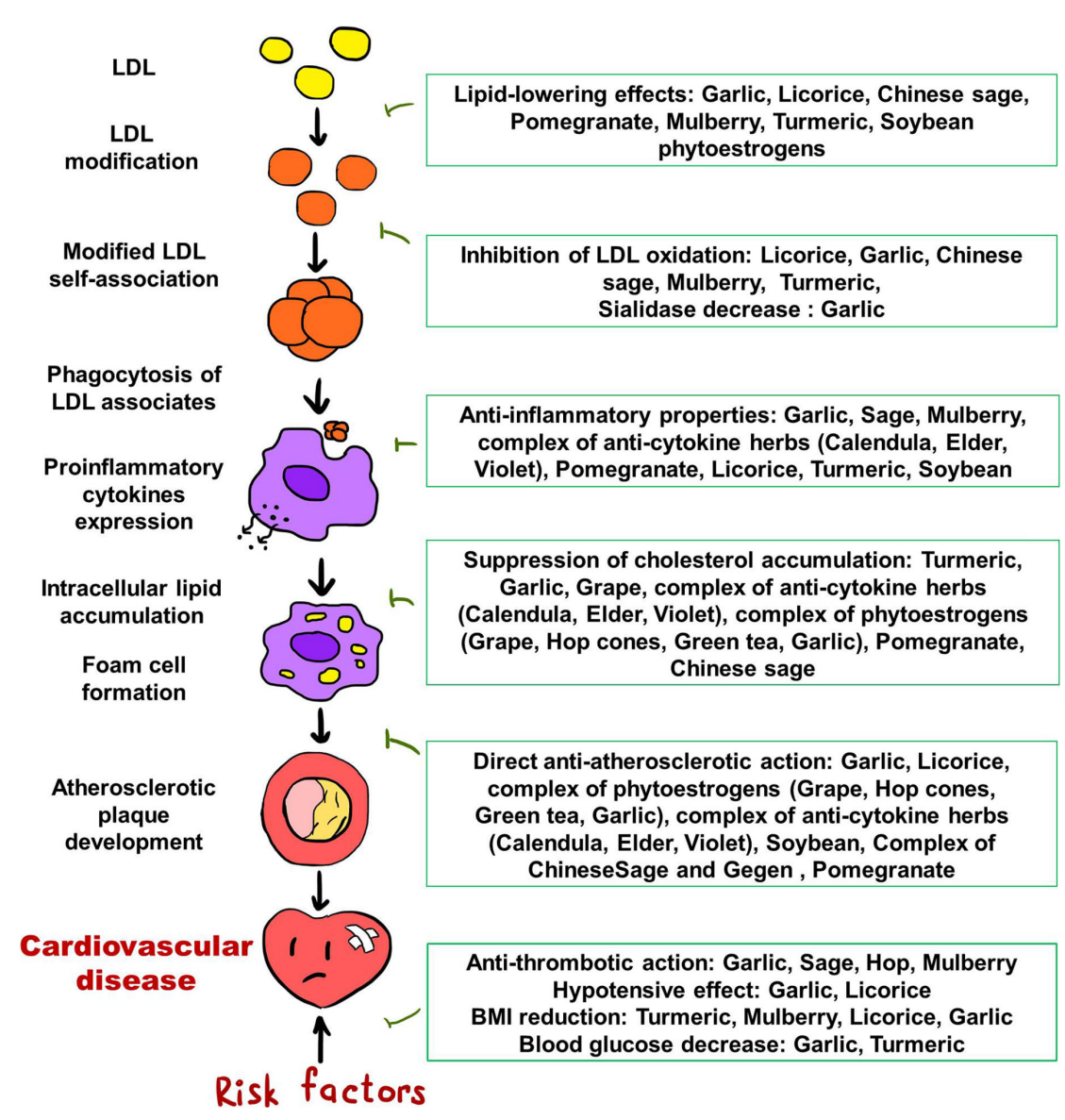

FIGURE 1 | Plausible effects of medicinal plants on different stages of atherosclerosis development. 
from licorice (Glycyrrhiza glabra L.). Glabridin possesses antiinflammatory action by preventing TNF- $\alpha$-stimulated gene expression of VCAM-1 (vascular cell adhesion molecule-1) and ICAM-1 (intercellular adhesion molecule-1) via blocking JNK

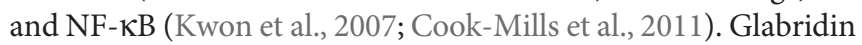
possesses anti-cytokine activity, since it suppresses the LPSstimulated secretion of inflammatory cytokines TNF- $\alpha$ and IL$1 \beta$ in microglial cells (Park et al., 2010) and TNF- $\alpha$ - stimulated production of adhesion molecules in human umbilical vein endothelial cells (Jong et al., 2006; Chang et al., 2010). In addition to anti-inflammatory properties, glabridin can inhibits LDL oxidation by suppression of 2,2-azobis(2-amidinopropane) hydrochloride (AAPH)-stimulated production of cholesteryl linoleate hydroperoxide in LDL, and the reduction of LDL oxidation by glabridin was confirmed in ex vivo model: the ability to oxidize LDL in cell culture of mice peritoneal macrophages decreased after accumulation of glabridin (Rosenblat et al., 1999; Kang et al., 2015).

Garlic (Allium sativum L.) possesses multiple antiatherosclerotic effects. Allicor, garlic powder, inhibits inflammation signaling (like TNF, IL-1 $\beta$, ICAM-1, and HLADR expression and secretion) (Karagodin et al., 2016a). Garlic also exhibits hypotensive activity through the inhibition of angiotensin-converting enzyme (Asdaq and Inamdar, 2010), positive activation of the growth suppressor p27, descent of ERK1/2 phosphorylation (Castro et al., 2010), and downregulation of angiotensin II receptor (Mansour et al., 2013), reduction of vasoconstrictor prostanoids synthesis (Al-Qattan et al., 2001), stimulation of hydrogen sulfide (H2S) production (Al-Qattan et al., 2006), and regulation of endothelial nitric oxide (NO) synthesis (Ried and Fakler, 2014; Karagodin et al., 2016a). Garlic antithrombotic activity revealed through suppression of cyclooxygenase (Ali et al., 2000), diminished production of thromboxane B2 and vasoconstrictors like prostaglandin E2 and leukotriene C4 by platelets (Vilahur and Badimon, 2013), control of membrane phospholipases activity, and serotonin and coagulation factor IV secreting from platelets (Rahman, 2007). Aged garlic extract also prevented platelet aggregation by increasing cyclic nucleotides (Allison et al., 2012; Rahman et al., 2016), the quantity of both extracellular ATP and intraand extracellular thromboxane B2, by inhibiting GPIIb/IIIa receptor and fibrinogen binding, and by abolishing phosphorylation of collagen-induced ERK, JNK, and p38 (Morihara and Hino, 2017). Moreover, antioxidant activity, synthesis of connective tissue matrix components, and cellular proliferative activity are suppressed, and LDL becomes less prone to oxidation thanks to the anti-atherosclerotic activity of garlic extracts (Orekhov et al., 2013; Orekhov et al., 2015). Garlic powder preparations inhibited neointimal thickening in cholesterol-fed rabbit models (Sobenin et al., 2016a). Garlic powder obviated neointimal thickening in cholesterol-fed rabbits, and Allicor (garlic tablet) decreased the accumulation of cholesterol in cell cultures incubated with serum from patients with atherosclerosis (Orekhov et al., 2013; Orekhov et al., 2015; Sobenin et al., 2016a). Garlic extracts were demonstrated to impede sialidase activity in blood plasma, which causes atherogenic LDL formation (Aksenov et al., 2007; Venkataiah et al., 2016; Sobenin et al., 2017). Diallyl disulfide, a component of garlic oil, is able to inhibit 3-hydroxy-3-methylglutaryl CoA reductase (HMGR) activity due to significant decrease in the mRNA levels and protein expression of HMGR. (Rai et al., 2009). It was shown in rat models that garlic consumption led to downregulation of genes related to lipid metabolism: acetyl-CoA carboxylase (ACC), acyl-CoA cholesterol acyltransferase (ACAT), HMGR, fatty acid synthase (FAS), sterol regulatory element-binding protein-1c (SREBP-1c), and glucose-6phosphate dehydrogenase (G6PD) (Ha et al., 2015). Thus, garlic can cause the lowering of total cholesterol and triglycerides in the blood. It was reported in review of Shouk et al., that bioactive components of garlic possess antihypertensive activity through modulating various parameters implicated in the pathogenesis of hypertension, in particular, proliferation of vascular smooth muscle cells, nitric oxide bioavailability, hydrogen sulfide production, angiotensin converting enzyme activity, expression of nuclear factor- $\kappa \mathrm{B}$ (Shouk et al., 2014).

Phytoestrogens, plant-derived estrogens, can be used as an alternative estrogen replacement therapy for Cardiovascular disease (CVD) and osteoporosis prevention. Phytoestrogens, bioflavonoids characterized by similar structure to endogenous estrogens, can be found in different plants like soybean, pomegranate, spinach, etc (Franke et al., 1998; Kirichenko et al., 2017). Soybean contents a lot of isoflavones, which are selective estrogen receptor modulators (Franke et al., 1998; Oseni et al., 2008). Soybean consumption leads to the suppression of VCAM-1 expression (Kim et al., 2019) and elevation of the number of endothelial progenitor cells thus improving endothelial function (Chan et al., 2011). The flavanone 8prenylnaringenin from hop flowers possessed anti-aggregatory and anti-adhesive effects on human platelets, acting as an inhibitor of platelet aggregation stimulated by different agonists and platelet adhesion to collagen matrix, a direct activator of intracellular cAMP and cGMP production, and VASP phosphorylation promoter (Di Vito et al., 2012). Grape phytoestrogens consumption helps to reduce serum atherogenicity, namely, intracellular cholesterol accumulation in primary culture of human blood-derived monocytes (Nikitina et al., 2006).

In traditional Chinese medicine plants and their mixtures are actively used to treat cardiovascular diseases, including atherosclerosis. Recently researches on the functions of several popular Chinese plants were conducted but they didn't reveal the exact mechanism of action for many of these plants (Hao et al., 2015; Hao et al., 2017; Sedighi et al., 2017). In overall, Chinese plants may influence all pathogenic mechanisms underlying atherosclerosis, including lowering plasma LDL-cholesterol, reduction of oxidative stress in endothelium, attenuation of endothelial proinflammatory activation, inhibition of endothelial cells apoptosis, anti-inflammatory activity, activation of macrophages M2 polarization, decrease of foam cells formation, inhibition of platelet activation and aggregation. Most important Chinese plants are turmeric (Curcuma longa L.), 
Chinese sage or danshen (Salvia miltiorrhiza Bge), flowering plants of the barberry family (Berberidaceae family Juss.), green chireta (Andrographis paniculate Nees.), oak leaves (Quercus dentata Thunb.), garlic (Allium sativum L.), and jiaogulan (Gynostemma pentaphylla Thunb.) (Qiao and Chen, 2018). For example, curcuma may reduce cholesterol accumulation in arterial wall by inhibiting SR-A-mediated oxidized LDL uptake and promoting cholesterol efflux through activation of AMPKSIRT1-LXR $\alpha$ signaling (Zhao et al., 2012; Lin et al., 2015). Curcumin, which is an active component of turmeric, exhibits its anti-inflammatory properties via negative regulation of proinflammatory interleukins (IL-1, IL-2, IL-6, IL-8, and IL-12), cytokines (TNF-a), MCP-1) by inhibiting expression of JAK/ STAT signaling pathway. Moreover, curcumin may regulate the inflammatory response by suppressing activity of iNOS, COX-2, lipoxygenase, and xanthine oxidase, and activation of NF-kB (Kocaadam and Şanlier, 2017).

Chinese sage has a potential to inhibit foam cell formation caused by oxidized LDL through down-regulating of CD36 expression and up-regulating of Prdx1/ABCA1 signaling (Bao et al., 2012; Yang et al., 2018). Tanshiones, a group of lipophilic abietane diterpene compounds from Salvia miltiorrhiza, stabilized plaques or even attenuated plaque formation through inhibition of NF-kB pathway (Liu et al., 2015; Yang et al., 2016; Zhao D. et al., 2016; Zhao W. et al., 2016), suppressed endothelial apoptosis via IncRNA TUG1 up-regulating miR-26a expression (Chen et al., 2016). Tanshiones also protect from oxidation stress by increasing NO production and superoxide dismutase activity, inhibiting ROS production (Lin et al., 2006; Yang et al., 2011; Chen et al., 2012; Joe et al., 2012). Salvia compounds possess anti-thrombotic activity since they inhibit phosphoinositide 3-kinase and that's why decrease platelet activation (Huang et al., 2010). Chinese sage and gegen (Pueraria lobate Willd.) radix is a herbal formula suppress the expression of ICAM-1 and VCAM-1 and production of MCP-1 in TNF- $\alpha$ stimulated human umbilical vein endothelial cells (Koon et al., 2011). Sage also has antihypertensive activity as it was shown that sage extract increased nitric oxide production and relaxed endothelium-intact rings in experiments on isolated thoracic aorta from rats (Anwar et al., 2017).

Berberine from Huang Liang (Coptis chinensis Franch.) decreased plasma LDL-cholesterol by upregulating LDLR, and apoE expression and downregulating HMGR expression (Kong et al., 2004; Chang et al., 2012). Berberine exhibits cytoprotective effect on endothelial cells (EC) by blocking JNK phosphorylation (Guo et al., 2016) and increases plaque stability by inhibiting MMP-9 and EMMPRIN by suppressing the activation of p38 pathway (Huang et al., 2011) and NF-kB activation (Huang et al., 2012). Foam cell formation can be reduced by berberine via enhancing LXR $\alpha$-ABCA1-dependent cholesterol efflux (Lee et al., 2010). Berberine activates the AMPK-SIRT1-PPAR- $\gamma$ pathway and, respectively, reduces the uptake of oxidized LDL (Chi et al., 2014). Coptis chinensis extract can induce macrophage autophagy via AMPK/mTOR and PI3K/AKT/ mTOR pathways (Fan et al., 2015; Kou et al., 2017). More Chinese herbs, their influence on atherosclerosis and underlying mechanism were thoroughly described in recent reports (Zhao et al., 2012; Hao et al., 2015; Qiao and Chen, 2018).

Mulberry (Morus alba L.) leaf extract provides anti-platelet and antithrombotic effects via blocking of platelet activation and aggregation, thromboxane B2 formation, serotonin secretion, and thrombus formation. Granule secretion and extracellularsignal-regulated kinase and Akt phosphorylation underlie the mechanism of this anti-platelet activity (Kim et al., 2014). Mulberry leaf extract protects lymphocyte DNA from oxidative damage, prevents ROS-mediated endothelial cell dysfunction via downregulating intracellular redox-dependent signaling pathways. It also has anti-inflammatory effects through the modulation of AP-1, NF- $\kappa \mathrm{B}$, PPARs, and STAT3 signaling (Chao et al., 2013).

The last but not the least medicine plant in this review is pomegranate (Punica granatum L.), which extracts possess multiple anti-atherosclerotic activities. Thus, ellagic acid promotes cholesterol removal by regulating LXR/PPARABCA1 pathway (Zhao S. et al., 2016). Pomegranate peel extract and punicalgin up-regulate mRNA expression of LXR $\alpha$ and ABCA1 (Zhao et al., 2014). Ellagic acid and punicalagin cause anti-oxidant effect by reducing ROS level produced by mitochondria (Hwang et al., 2010; Zou et al., 2014). Moreover, pomegranate possesses obvious anti-inflammatory effect since pomegranate peel, flower, and seed oil may reduce plasma levels of IL-6 and TNFa, pomegranate flower may increase the antiinflammatory cytokine IL-10 (Harzallah et al., 2016) and, in addition, pomegranate extract diminishes the translocation of NF- $\mathrm{KB}$ from the cytosol to the nucleus (Mandal et al., 2017). Pomegranate ellagic acid, peel polyphenols, and punicalagin lower LPS-induced pro-inflammatory cytokine activation (Du et al., 2018).

The most common pathogenetic mechanisms of antiatherosclerotic action of medicinal plants are presented in Table $\mathbf{1}$.

\section{REDUCTION OF THE ATHEROSCLEROSIS RISK FACTORS WITH MEDICINAL PLANTS}

Conventional risk factors for cardiovascular diseases, in particular, hyperlipidemia, arterial hypertension, type 2 diabetes mellitus (T2D), smoking, obesity, etc., explain more than $50 \%$ of the variability of atherosclerosis, so represent the most significant factor in atherosclerosis development. In this regard, cardiovascular risk factors are the most important target in the process of timely prevention and treatment of atherosclerosis.

Medicinal plants have long been widely studied as antiatherosclerotic agents; to date, sufficient data have been obtained on the effect of natural products on various traditional risk factors (Table 2). Nowadays natural products are known to have the greatest potential for long-term prevention of atherosclerosis. 
TABLE 1 | Possible Anti-Atherosclerotic Mechanisms of Action of Medicinal Plants.

Effect Plants/complex of plants Mechanism

Anti-inflammatory (suppression of 1) Inflaminat (Calendula (Calendula officinalis L.) + inflammatory mediators expression and signal pathway) Black Elder (Sambucus nigra L.) + Violet (Viola tricolor L.)) Licorice (Glycyrrhiza glabra L.)

Garlic (Allium sativum L.)

Turmeric (Curcuma longa L.)

Chinese sage (Salvia miltiorrhiza) Chinese sage (Salvia miltiorrhiza) and gegen (Pueraria lobate Willd.)

Huang Liang (Coptis chinensis Franch.)

Mulberry (Morus alba L.)

Pomegranate (Punica granatum L.)

Antioxidant (Inhibition of LDL oxidation)

Licorice extract (Glycyrrhiza glabra L.)

Chinese sage (Salvia miltiorrhiza Bge.)

Mulberry (Morus alba L.)

Pomegranate (Punica granatum L.)

Antithrombotic activity (prevention of platelet aggregation)

Garlic (Allium sativum L.)

Hop flowers (Hunulus lupulus L.)

Chinese sage (Salvia miltiorrhiza Bge.) Mulberry (Morus alba L.)

Garlic (Allium sativum L.)

Antracellular cholestero accumulation in cultured cells)
Inhibiting expression of IL-1 $\beta$ and TNF (Kirichenko et al., 2016)

- JNK and NF-kB signaling blocking (Kwon et al., 2007; Cook-Mills et al., 2011)

- TNF- $\alpha$, IL-1 $\beta$ production suppression (Park et al., 2010)

- Adhesion molecules suppression (Jong et al., 2006; Chang et al., 2010)

- Inflammation signaling inhibiting (like TNF- $\alpha$, IL-1 $\beta$, ICAM-1 and HLA-DR) (Karagodin et al., 2016a)

- Inhibiting expression of JAK/STAT signaling pathway (Kocaadam and Şanlier, 2017)

- Suppressing activity of iNOS, COX-2, lipoxygenase, and xanthine oxidase (Kocaadam and Şanlier, 2017)

- Activation of NF-kB (Kocaadam and Şanlier, 2017)

- Inhibition of NF-kB pathway (Yang et al., 2016; Zhao D. et al., 2016)

- Inhibition of adhesion molecules expression (Koon et al., 2011)

- Suppression of MCP-1secretion (Koon et al., 2011)

- JNK phosphorylation (Guo et al., 2016)

- Activation of p38 pathway (Huang et al., 2011)

- NF-kB activation (Huang et al., 2012)

- Modulation of AP-1, NF-kB, PPARs, and STAT3 signaling (Kim et al., 2014)

- Reduction plasma levels of IL-6 and TNFa and increase IL-10 (Harzallah et al., 2016)

- Inhibiting of LDL oxidation by suppression of AAPH-induced formation of cholesteryl linoleate hydroperoxide in LDL particle (Rosenblat et al., 1999; Kang et al., 2015)

- Inhibiting ROS production (Lin et al., 2006; Huang et al., 2010; Yang et al., 2011; Joe et al., 2012)

- Down-regulating intracellular redox-dependent signaling pathways (Chao et al., 2013)

- Reducing ROS level production by mitochondria (Harzallah et al., 2016; Mandal et al., 2017)

- Suppression of cyclooxygenase-2 (Ali et al., 2000)

- Reducing synthesis of vasoconstrictors such as prostaglandin E2 and leukotriene C4 (Vilahur and Badimon, 2013)

- Regulation of serotonin and coagulation factor IV production (Rahman, 2007)

- Supression of platelet aggregation by increasing of cyclic nucleotides (Allison et al., 2012; Rahman et al., 2016)

- Inhibiting the GPIIb/Illa receptor and fibrinogen binding (Morihara and Hino, 2017)

- Suppressing the phosphorylation of collagen-induced ERK, JNK and p38 (Morihara and Hino, 2017)

- Increasing of intracellular CAMP and cGMP lexpression, promotion of VASP phosphorylation (Di Vito et al., 2012)

- Inhibition of phosphoinositide 3-kinase (Huang et al., 2010)

- Blocking of platelet activation and aggregation, thromboxane B2 formation (Kim et al., 2014)

- Down-regulation of HMGR, FAS, SREBP-1c, G6PDH, acetyl-CoA carboxylase, and ACAT (Rai et al., 2009)

- Inhibiting HMGR activity (Venkataiah et al., 2016)

- Inhibiting of SR-A-mediated oxidized LDL uptake (Zhao et al., 2012; Lin et al., 2015)

- Promoting ABCA1-dependent cholesterol efflux through activation of AMPKSIRT1-LXR $\alpha$ signaling (Zhao et al., 2012; Lin et al., 2015)

Chinese sage (Salvia miltiorrhiza Bge.)

Huang Liang (Coptis chinensis Franch.)

- Up-regulating of LDLR (Kong et al., 2004; Chang et al., 2012)
- Down-regulating of CD36 expression (Bao et al., 2012; Yang et al., 2018)

- Up-regulating of Prdx1/ABCA1 signaling (Bao et al., 2012; Yang et al., 2018)

- Up-regulating apoE expression (Kong et al., 2004; Chang et al., 2012)

- Down-regulating HMGR expression (Kong et al., 2004; Chang et al., 2012) 
TABLE 1 | Continued

\begin{tabular}{|c|c|c|}
\hline Effect & Plants/complex of plants & Mechanism \\
\hline & & - Enhancing LXR $\alpha-A B C A 1-d e p e n d e n t$ cholesterol efflux (Lee et al., 2010) \\
\hline & & - Activating the AMPK-SIRT1-PPAR- $\gamma$ pathway (Chi et al., 2014) \\
\hline & Pomegranate (Punica granatum L.) & - Regulating LXR/PPAR-ABCA1 pathway (Zhao S. et al., 2016) \\
\hline & & - Up-regulation of LXR $\alpha$ and ABCA1 expression (Zhao et al., 2014) \\
\hline \multirow[t]{6}{*}{ Hypotensive effects } & Garlic (Allium sativum L.) & - Inhibition of angiotensin-converting enzyme (Asdaq and Inamdar, 2010) \\
\hline & & - Activation of the growth suppressor p27 (Castro et al., 2010) \\
\hline & & - Down-regulation of angiotensin II receptor (Mansour et al., 2013) \\
\hline & & - Reduction of vasoconstrictor prostanoids synthesis (Al-Qattan et al., 2001) \\
\hline & & - Stimulation of H2S production (Al-Qattan et al., 2006) \\
\hline & & $\begin{array}{l}\text { - Regulation of endothelial NO synthesis (Ried and Fakler, 2014; Karagodin } \\
\text { et al., 2016b) }\end{array}$ \\
\hline
\end{tabular}

Chinese medicine has achieved significant results in reducing the risk factors of atherosclerosis. Studies of the traditional Chinese formula Danshen Salvia miltiorrhiza + Gegen Radix puerariae in showed a significant decrease in plasma total cholesterol (TC) and LDL in postmenopausal women with hypercholesterolemia after 12 months of daily intake of $1 \mathrm{~g}$ of the drug in a randomized placebo-controlled trial (Koon et al., 2013). A randomized, double-blind, placebo-controlled pilot trial involving patients with type 2 diabetes showed that daily intake of $9 \mathrm{~g}$ of YH1-formula (Rhizoma Coptidis (Coptis chinensis Franch.) and Shen-Ling-Bai-Zhu-San (complex of Salvia miltiorrhiza Bge., Atractylodis macrocephalae DC., Glycyrrhiza glabra L., Poria Pers., Citrus reticulata Blanco., Nelumbinis Adans., Platycodon A.DC., Amomum Roxb., Coix lacryma-jobi L., Dolichos L.) led to a significant reduction of not only HbAlc and glucose levels, but also plasma Tg, TC, LDL levels (Huang et al., 2019). Another study of the JTTZ formula \{Chinese sage [Salvia miltiorrhiza Bge.], Aloe vera [Aloe vera (L.) Burm.f.], Huanglian [Coptis chinensis Franch.], Rhizoma Anemarrhenae [Anemarrhena asphodeloides Bge.], red yeast [Monascus purpureus Went., 1895], Kugua [Momordica charantia L.], Wuweizi [Schisandra chinensis (Turcz.) Baill.], and dried ginger [Zingiber officinale Roscoe.]\}, involving patients with type 2 diabetes, not only reduced $\mathrm{HbAlc}$ and normalized the lipid profile of blood plasma, but also led to weight loss (Yu et al., 2018).

Garlic powder is characterized by significant effects on many risk factors of atherosclerosis. In a randomized placebocontrolled trial performed by Zeb F. et al., the weight loss of the subjects was demonstrated (Zeb et al., 2018). In this and other studies, administration of garlic powder caused a significant lipid-lowering effect (Higashikawa et al., 2012; Ahmad Alobaidi, 2014; Alali et al., 2017; Xu et al., 2018; Choudhary et al., 2018). Several clinical trials also confirmed hypotensive effect of garlic. In particular, it was shown in the randomized, placebo-controlled, clinical study of MahdaviRoshan et al. that 3-months administration of garlic powder pills (equal to $800 \mathrm{mg}$ garlic daily) results in significant reduction of systolic blood pressure by $12.0 \mathrm{~mm} \mathrm{Hg}$ in patients with mild arterial hypertension in comparison with placebo (MahdaviRoshan et al., 2016). A similar hypotensive effect was demonstrated by other randomized placebo-controlled clinical studies (Ashraf et al., 2013; Al Disi et al., 2016). Treatment with $600 \mathrm{mg}$ garlic powder pills (Allicor) led to a significant decrease of both systolic and diastolic blood pressure by 7.0 and $3.8 \mathrm{mmHg}$ (95\% CI: 2.7-4.8), respectively (Sobenin et al., 2009). Interestingly, Aalami-Harandi $\mathrm{R}$ et al. in their randomized, double-blind, placebo-controlled trial at risk for pre-eclampsia involving pregnant women demonstrated that administration of $400 \mathrm{mg}$ garlic daily for 9 weeks resulted in reduced levels of serum high sensitivity C-reactive protein (hs-CRP) (-1425.90 versus $1360.50 \mathrm{ng} / \mathrm{ml}, \mathrm{p}=0.01$ ) in comparison with placebo (Aalami-Harandi et al., 2015).

Phytoestrogens are characterized by lipid-lowering and hypotensive effects. Villa $\mathrm{P}$ et al. in their pilot randomized trial involving ninety women in menopausal transition showed that administration of phytoestrogen substances in addition to vitamins and passionflower herbal preparation during 6 months led to TC decrease in blood plasma (Saadati et al., 2019). Eight-week of soy nut diet helped to decrease of fasting blood glucose as well as to improve blood lipids profile, significantly decreasing TC and LDL (Fogelman et al., 2016). Other 6-month randomized controlled trial showed the LDL and hs-CRP reduction effects of daily $40 \mathrm{~g}$ phytoestrogen-rich soy flour treatment of equol-producing postmenopausal women (Zeb et al., 2018). Other randomized controlled study has shown the hypotensive effect of isoflavones manifesting in a significant decrease of blood pressure (Alali et al., 2017). In a double-blind, randomized, placebo-controlled trial, $50 \mathrm{mg}$ of isoflavone-rich preparation Rimostil resulted in significant serum LDL cholesterol reduction in perimenopausal women (Clifton-Bligh et al., 2015). Plant-derived flavonoids are welldocumented to play important vasculoprotective role and it was demonstrated in several randomized controlled trials that catechins and quercetin have significant blood pressure lowering effect (Maaliki et al., 2019).

Turmeric also has lipid, hs-CRP, BMI, and glucose lowering effects observing during treatment of type 2 diabetes. Curcumin, a natural polyphenol from turmeric was tested in a randomized, double-blind, placebo-controlled trial on patients with diabetes who consumed $1,5 \mathrm{~g}$ curcumin daily for 10 weeks. Adibian $\mathrm{M}$ et al. have found significant hs-CRP and Tg-lowering effects (Adibian 
TABLE 2 | Medicinal Plants in Cardiovascular Risk Improvement.

Plant/complex of plants

References

Chinese sage (Salvia miltiorrhiza Bge.) and Gegen Radix (Pueraria lobate Willd.)

YH1 (Coptis chinensis Franch., Salvia miltiorrhiza Bge., Atractylodis macrocephalae DC., Glycyrrhiza glabra L., Poria Pers., Citrus reticulata Blanco., Nelumbinis Adans., Platycodon A.DC., Amomum Roxb., Coix lacryma-jobi L., Dolichos L.) JTIZ formula (Salvia miltiorrhiza Bge., Aloe vera (L.) Burm.f., Coptis chinensis Franch., Anemarrhena asphodeloides Bge., Monascus purpureus Went., 1895, Momordica charantia L. Schisandra chinensis (Turcz.) Baill., Zingiber officinale Roscoe. Allicor (Allium sativum L.)

Garlic (Allium sativum L.)

Raw crushed garlic

Aged black garlic

Galois (garlic powder tablet)

Phytoestrogens (Glycine max (L.) Merr. + Passiflora L.) with vitamins

Soy nut (Glycine max (L.) Merr.)

Karinat (Vitis vinifera L., Camellia sinensis L., Hunulus lupulus L., Allium sativum L.)

Isoflavones from soybean (Glycine max (L.) Merr.)

Curcumin

Curcuminoids

Curcumin formulation

Licorice root extract 12-months randomized, placebo-controlled trial in postmenopausal women with

hypercholesterolemia:

- lipid-lowering effect (TC -6.2\% and LDL - 7.3\%)

12-week randomized, double-blind, placebo-controlled pilot trial in 46 patients with T2D:

- reduction in $\mathrm{HbA} 1 \mathrm{c}(-11.1 \%)$

- postprandial glucose decrease (-26.2\%)

- lipid-lowering effect ( $\mathrm{Tg}-29.5 \%, \mathrm{TC}-21.6 \%$, LDL - 17.4\%)

12-week randomized, positive-controlled (metformin), open-label trial in 450 patients with T2D, obesity and hyperlipidemia:

- reduction of $\mathrm{HbA} 1 \mathrm{c}(-0.75 \pm 1.32 \%)$

- lipid-lowering effect $(\mathrm{Tg}-0.64 \pm 2.37 \mathrm{mmol} / \mathrm{L})$

- Weight decrease $(-2.47 \pm 2.71 \mathrm{~kg})$

4-week randomized, double-blind, placebo-controlled trial in 42 men:

- lipid-lowering effect (TC - 7.6 $\pm 2.4 \%$, LDL - $11.8 \pm 4.5 \%$, Tg $-7.7 \pm 9.0 \%$ )

16 -weeks randomized, placebo-controlled, double-blind trial in 84 men with moderate hypertension:

- hypotensive (SBP $-9.3 \pm 0.7 \mathrm{mmHg}$, DBP $-3.8 \pm 0.5 \mathrm{mmHg}$ )

4-weeks randomized double-blinded placebo-controlled outpatient clinical trial of $60 \mathrm{~T} 2 \mathrm{D}$ patients:

- blood glucose decrease $(-1.8 \pm 0.5 \mathrm{mmol} / \mathrm{l})$

6-weeks randomized, double-blind, placebo-controlled trial in 51 patients with obesity:

- LDL-lowering effect ( $p=0.05)$

4-weeks open-label trial in 40 patients with metabolic syndrome:

- blood pressure decrease $(p<0.001)$

- Tg -lowering effect $(p<0.01)$

- blood glucose decrease $(p<0.001)$

- HDL increase $(p<0.001)$

12-weeks open-label trial in 60 patients with with mild hypercholesterolemia:

- HDL increase $(\mathrm{p}<0.001)$

3-months randomized, double-blind, placebo-controlled trial in 56 patients with coronary artery disease:

- SBP decrease $(p=0.04)$

6-months pilot randomized trial in 90 women in menopausal transition:

- TC-lowering effect $(p<0.05)$

8-week randomized placebo-controlled trial in 70 patients with T2D

- lipid-lowering effect $(\mathrm{TC}(\mathrm{p}<0.01)$ and LDL $(\mathrm{p}=0.01)$ decrease)

- blood glucose decrease ( $(p=0.03)$

12-months randomized double-blind placebo-controlled study in 157 postmenopausal women:

- lipid-lowering effect (TC -6.3\% ( $p=0.011)$, LDL -7.6\% ( $p=0.040)$

2-year double-blind randomized study in 200 early postmenopausal women:

- SBP-reduction $(-3.2 \mathrm{mmHg}, \mathrm{p}<0.01)$

10-weeks randomized double-blind placebo-controlled trial in 44 T2D patients:

- hs-CRP decrease $(-2.5 \pm 4.3 \mathrm{mg} / \mathrm{L})$

- Tg-lowering $(-14.2 \pm 30.6 \mathrm{mg} / \mathrm{dl})$

8-weeks 80 hyperlipidemic in T2D patients:

- BMl and lipid-lowering effect (Tg, TC and LDL decrease, $p<0.05$ )

3-months randomized double-blind placebo-controlled trial in $100 \mathrm{~T} 2 \mathrm{D}$ patients:

- blood glucose decrease, $-9 \pm 16 \mathrm{mg} / \mathrm{dL}$

12 -weeks randomized, placebo-controlled trial in 50 patients with non-alcoholic fatty liver disease

- $\quad$ BMl decrease $(p<0.001)$

- TNF- $\alpha$ reduction $(<0.001)$

12-months randomized placebo-controlled study in 110 patients with hypercholesterolemia:

- lipid-lowering effect (TC -7.8\%, LDL -4.9\%)

- hypotensive (SBP $-13 \pm 13 \mathrm{mmHg}, \mathrm{DBP}-8 \pm 10 \mathrm{mmHg}$ )
Koon et al. (2013)

Huang et al. (2019)

Yu et al., (2018)

Sobenin et al. (2008a)

Sobenin et al. (2009)

Sobenin et al. (2008)

Xu et al. (2018)

Choudhary et al. (2018)

Jung et al. (2014)

Mahdavi-Roshan et al. (2016)

Villa et al. (2017)

Sedaghat et al. (2019)

Myasoedova et al. (2016)

Sathyapalan et al. (2018)

Adibian et al. (2019)

Adab et al. (2019)

Panahi et al. (2018)

Saadati et al. (2019)

Fogelman et al.

(2016) 
et al., 2019). Adab $\mathrm{Z}$ et al. have demonstrated that administration of turmeric (2,1 g powdered rhizome of turmeric daily for 8 weeks) significantly decreased BMI as well as plasma Tg, TC, and LDL (Adab et al., 2019). Panahi Y et al. also observed lipid-lowering effect in their randomized controlled trial using curcuminoids ( $1 \mathrm{~g}$ / day plus piperine $10 \mathrm{mg}$ /day) treatment of diabetes patients for 12 weeks (Panahi et al., 2018). Finally, a treatment with amorphous dispersion curcumin formulation $(500 \mathrm{mg}$ /day equivalent to 70 mg curcumin) of non-alcoholic fatty liver patients for 8 weeks resulted in BMI-reduction as well as plasma $\mathrm{Tg}$, LDL, and glucose levels lowering (Saadati et al., 2019).

In the placebo-controlled clinical study of the effect of 1-year licorice root extract consumption on cardiovascular risk factors, beneficial results were demonstrated, namely, the significant reduction of TC and LDL levels as well as hypotensive activity (Fogelman et al., 2016).

\section{POTENTIAL DIRECT ANTI- ATHEROSCLEROTIC EFFICACY OF MEDICINAL PLANTS}

The intima-media thickness of common carotid arteries is often used as a direct quantitative characteristic of atherosclerosis in clinical studies of the effectiveness of anti-atherosclerotic preparations. Currently, a number of medicinal plants have been studied using ultrasound scanning of the carotid arteries, that allows evaluating not only the indirect anti-atherosclerotic effect of these natural products by conversion of cardiovascular risk factors, but also studying their effect on carotid atherosclerosis development. Table 3 demonstrates the results of clinical trials evaluating the effect of medicinal plants on carotid IMT dynamics during long-term administration.

Several medicinal plants that are widely used in Chinese traditional medicine have been studied in clinical trials in patients with carotid atherosclerosis. Chinese herbal formulacomplex of Chinese sage (Salvia miltiorrhiza Bge.) and gegen radix (Pueraria lobate Willd.), that is often used for cardiovascular protection, caused the reduction of cIMT by $0.012 \mathrm{~mm}$ after 1 -year administration in 165 postmenopausal women (Kwok et al., 2014). Similar results of this herbal preparation $(D \& G)$ were obtained in a parallel study in highrisk hypertensive patients (Woo et al., 2013). Clinical study of the other Chinese complex: Reynoutria japonica rhizoma (Polygonum cuspidatum Siebold \& Zucc.) and hawthorn fruits (CrataegusTourn.ex L.) also demonstrates a significant reduction of cIMT after 6 months of follow-up (Liu et al., 2014).

Among a number of medicinal plants that have been studied in terms of anti-atherosclerotic mechanisms of action, garlic seems to be one of the most studied, its effectiveness is also investigated in clinical trials evaluating its direct antiatherosclerotic action on carotid atherosclerosis. For the first time in 1999 the effect of 4-year garlic powder dragees administration on atherosclerosis plaque dynamics was evaluated by B-mode ultrasound of carotid and femoral arteries and the significant reduction of plaque volume increase during follow-up period in garlic-receiving group in comparison with placebo was shown (Koscielny et al., 1999). Atherosclerosis Monitoring and Atherogenicity Reduction (AMAR) study was designed to evaluate effect of time-released garlic powder pills Allicor on dynamics of carotid IMT. It was shown in 2-year double-blinded placebo-controlled trial that Allicor administration leads to cIMT reduction by $-0.022 \mathrm{~mm}$ per year

TABLE 3 | Carotid IMT in Studies of the Direct Anti-atherosclerotic Effect of Medicinal Plants.

\section{Plants/complex of plants}

Chinese herbal formula (danshen Salvia miltiorrhiza Bge., gegen radix Pueraria lobate Willd.)

Chinese herb extraction (Reynoutria japonica rhizoma Polygonum cuspidatum Siebold \& Zucc., hawthorn fruits Crataegus Tourn.ex L.) Allicor (garlic powder Allium sativum L.)

\section{Garlic powder tablets (Allium sativum L.)}

Karinat (Vitis vinifera L., Camellia sinensis L., Hunulus lupulus L., Allium sativum L.) Soybean (Glycine max (L.) Merr.) - isoflavone soy protein

Inflaminat (Calendula flowers Calendula officinalis L., Black elder berries Sambucus nigra L., Violet herb Viola tricolor L.)

Licorice root extract (Glycyrrhiza glabra L.)

Pomegranate (Punica granatum L.)

\section{Carotid IMT dynamics}

\section{References}

12-months cIMT reduction: -0.012 mm Woo et al. (2013); Kwok et al. (2014)
$(p<0.001)$
6-months cIMT reduction $(p<0.05) \quad$ Liu et al. (2014)

annual cIMT change at 2-year study: Allicor -0.022 vs. placebo $+0.015 \mathrm{~mm} /$ year $(\mathrm{p}<0.05)$

3-months cIMT dynamics: Garlic $-0.009 \mathrm{~mm}$ vs. placebo $+0.004 \mathrm{~mm}$ 12-month cIMT progression: Karinat $+0.006 \mathrm{~mm}$ vs. placebo $+0.011 \mathrm{~mm}$ annual cIMT change at 2-year study: ISP +0.002 vs. placebo $+0.006 \mathrm{~mm} /$ year $(\mathrm{p}=0.05)$

annual cIMT change at 2-year study: Inflaminat +0.006 vs. placebo +0.022 $\mathrm{mm} /$ year $(\mathrm{p}=0.045)$

3-months cIMT dynamics: Licorice $-0.008 \mathrm{~mm}$ vs. placebo $+0.003 \mathrm{~mm}$
Karagodin et al. (2016a)

(clinical trial registration number NCT01734707, http://clinicaltrials.gov/)

Mahdavi-Roshan et al. (2013) (clinical trial registration number NCT01948453, http://clinicaltrials.gov/)

Myasoedova et al. (2016) (clinical trial registration number

NCT01742000, http://clinicaltrials.gov/)

Hodis et al. (2011)

Kirichenko et al. (2016)

(clinical trial registration number NCT01743404, http://clinicaltrials.gov/)

Fogelman et al. (2016)

Davidson et al. (2009)

(clinical trial registration number NCT00728299, http://clinicaltrials.gov/) 
while in placebo group the progression of cIMT was observed with mean annual rate $+0.015 \mathrm{~mm}(\mathrm{p}<0.001)$ (Orekhov et al., 2013; Karagodin et al., 2016b). Another study of garlic powder tablets efficacy on carotid atherosclerosis showed the similar beneficial data, cIMT dynamics differed significantly between verum and placebo groups ( $\mathrm{p}<0.001)$ : 3 -month cIMT reduction $-0.009 \mathrm{~mm}$ in garlic-administrated group vs. 3 -months cIMT progression $+0.004 \mathrm{~mm}$ in placebo-administrated group; only preliminary results of this study were published for this moment (Mahdavi-Roshan et al., 2013).

An important area of research is the correction of atherosclerotic changes in postmenopausal women. It is known that women of childbearing age are less likely to suffer from atherosclerosis than men of this age. However, after menopause, this situation evens out. There is evidence of the ability of preparations containing isoflavonoids (phytoestrogens) to inhibit the formation of new atherosclerotic lesions and slow down the development of existing ones. The data of some studies (Myasoedova et al., 2016; Sobenin et al., 2016b) indicate that the use of isoflavonoid-rich herbal preparations, such as Karinat (grape seeds Vitis vinifera L., green tea Camellia sinensis L., hop cone Hunulus lupulus L., garlic Allium sativum L.), has therapeutic potential for the prevention of cardiovascular disease in postmenopausal women and in the perimenopausal period. The significant reduction of annual rate of cIMT progression was demonstrated in 2-year double-blinded placebo-controlled study in postmenopausal women -0.006 vs. $0.011 \mathrm{~mm} /$ year in placebo group $(\mathrm{p}<0.001)$ (Myasoedova et al., 2016). Soybean [Glycine $\max$ (L.) Merr.] is one of the richest sources of phytoestrogens so it's widely used for therapy of climacteric syndrome and it's also successfully used for cardiovascular protection in women after menopause (Sathyapalan et al., 2018). In the study of Hodis HN et al. the annual rate of cIMT progression differed significantly in the group with isoflavone soy protein (ISP) supplementation in comparison with placebo and was +0.002 and $+0.006 \mathrm{~mm} /$ year, respectively, $(\mathrm{p}=0.05)$; but such effect was observed in subgroup of women within 5 years of menopause, and in the total group of men and women the difference in cIMT progression between ISP and placebo control was not significant (Hodis et al., 2011). It was shown in another study that higher habitual soy food consumption is associated with decreased cIMT in middle-aged Chinese adults, wherein a significant interaction between sex and soy food intake on cIMT was observed ( $\mathrm{p}=0.008$ ) (Zhang et al., 2008).

Several studies of the herbal preparation Inflaminat that suppresses inflammatory cytokines expression as well as inhibits intracellular cholesterol accumulation in ex vivo models as was described above, has been conducted. Based on them, an optimal dosage regimen of the preparation was developed to achieve a stable anti-inflammatory effect. In patients with subclinical atherosclerosis, a clinical study was designed to evaluate anti-atherosclerotic properties of Inflaminat. As a criterion for assessing the development of atherosclerotic lesions was also used the cIMT indicator. As it turned out, Inflaminat possesses direct anti-atherosclerotic activity since significantly reduces of the cIMT progression during 2-years of administration. It was demonstrated that annual rate of cIMT progression was $+0.006 \mathrm{~mm} /$ year in Inflaminat-treated group and $+0.022 \mathrm{~mm} /$ year in placebo group ( $p=0.045)$ (Kirichenko et al., 2016). Among other medicinal plants that possess multiple anti-atherosclerotic effects in atherosclerosis models, several products have been also studied in clinical trials of direct anti-atherosclerotic activity. In particular, in the clinical study of Fogelman Y. et al., the effect of 1-year licorice-root extract (Glycyrrhiza glabra L.) consumption on cIMT dynamics was examined in 94 participants aged $41-80$ years. It was demonstrated that cIMT reducted by $-0.008 \mathrm{~mm}$ in licorice-treated group and increased by $+0.003 \mathrm{~mm}$ in placebo group (Fogelman et al., 2016). In clinical trial of Davidson M.H. et al., the pomegranate juice consumption decreased cIMT progression only in patients with dyslipidemia, but not in total group (Davidson et al., 2009).

Based on this evidence in our knowledge prevention and treatment of atherosclerosis with medicinal plants has certain limitations. The most important fact is that natural products have multiple therapeutic effects, and it will be almost impossible to know which exact nature of the mechanism of action has led to a beneficial effect. This is especially true for natural complexes in which plants can potentiate and/or attenuate the effects of each other due to various multiple mechanisms of action. Almost all studies have a sufficient number of limitations, very few of them are registered, so it is difficult to assess the main outcome indicators and adverse reaction. Most researchers report that there are no side effects, but protocol requirements for recording any side effects are usually not given; moreover, possible interactions with prescription preparations practically are not describe. Therefore, given the importance of long-term prevention of atherosclerosis and reduction of cardiovascular risk, it is recommended to use the medicinal plants possessing pleiotropic anti-atherosclerotic effects in experimental studies those have shown atheroprotective activity in registered clinical trials.

\section{CONCLUSION}

Critical analysis of the current literature, demonstrate that the accumulated knowledge of traditional herbal based medicine and modern approaches to studying the action of medicinal plants open a veil of secrecy over the mechanisms of action and possible ways of creating and using preparations based on medicinal plants. Medicinal plants facilitate the treatment of atherosclerosis using different pathway and various mechanisms of the action, a number of medicinal plants have prospects for the prevention or treatment of atherosclerosis. However, direct anti-atherosclerosis activity of preparations based on garlic powder was studied wider than others natural products, their ameliorating effect on the progression of cIMT was proved in randomized double-blinded placebo-controlled trials, registrated on https:/clinicaltrials.gov/ 
(Hodis et al., 2011; Mahdavi-Roshan et al., 2013; Karagodin et al., 2016a Karagodin et al., 2016b). Garlic preparations have the most interesting and obvious cardio-protective properties since garlic is able to ameliorate the blood lipids profile by inhibiting cholesterol biosynthesis, reducing of LDL, modulate arterial hypertension, and inhibit platelet aggregation (Sobenin et al., 2008a; Sobenin et al., 2008b; Sobenin et al., 2009; Jung et al., 2014; Mahdavi-Roshan et al., 2016; Myasoedova et al., 2016; Villa et al., 2017; Choudhary et al., 2018; Sathyapalan et al., 2018; Panahi et al., 2018; Xu et al., 2018; Sedaghat et al., 2019; Adibian et al., 2019; Adab et al., 2019). In laboratory experiments, garlic extract inhibits proliferative and inflammatory cellular reactions, possesses anti-cytokine properties, has pronounced antioxidant activity, so reduces the oxidation of LDL, activates the hydralase of cholesterol esters and inhibit ACAT, so reduces the content of cholesterol esters in cells. Thus, currently garlic seems to be the most promising plant for atherosclerosis prevention and treatment. Further comprehensive study of the mechanisms of influence of natural products on key links in the chain of development of atherosclerosis is an important and necessary step on the way to the development of new safe and effective preparations based on medicinal plants. But even modern data already indicate the possibility of using many medicinal plants as an additional therapy for patients with atherosclerosis and as a preventive measure for subjects with high cardiovascular risk.

\section{AUTHOR CONTRIBUTIONS}

AO and GA conceived and designed the review. TK, VS, NN, IS, VT, and P-YL contributed with the bibliographic research. TK, VS, AM, and NN wrote the manuscript. TK and IS provided table design. P-YL, VT, AO, and GA-review final version approval. AO, VT, and GA also contributed with the paper organization.

\section{FUNDING}

This work was supported by Russian Science Foundation (Grant \#19-15-00010). This research was also supported within the framework of the grant provided by CSP Ministry of the Health Russian Federation, and by the IPAC RAS State Targets Project \# 0090-2019-0005" for Gjumrakch Aliev. This work partially was also supported by the Russian Academic Excellence Project "5-100" for the Sechenov University, Moscow, Russia (for Gjumrakch Aliev and Vadim V. Tarasov).

\section{REFERENCES}

Aalami-Harandi, R., Karamali, M., and Asemi, Z. (2015). The favorable effects of garlic intake on metabolic profiles, hs-CRP, biomarkers of oxidative stress and pregnancy outcomes in pregnant women at risk for pre-eclampsia: randomized, double-blind, placebo-controlled trial. J. Matern. Fetal Neonatal Med. 28 (17), 2020-2027. doi: 10.3109/14767058.2014.977248

Adab, Z., Eghtesadi, S., Vafa, M. R., Heydari, I., Shojaii, A., Haqqani, H., et al. (2019). Effect of turmeric on glycemic status, lipid profile, hs-CRP, and total antioxidant capacity in hyperlipidemic type 2 diabetes mellitus patients. Phytother. Res. 33 (4), 1173-1181. doi: 10.1002/ptr.6312

Adibian, M., Hodaei, H., Nikpayam, O., Sohrab, G., Hekmatdoost, A., and Hedayati, M. (2019). The effects of curcumin supplementation on highsensitivity C-reactive protein, serum adiponectin, and lipid profile in patients with type 2 diabetes: a randomized, double-blind, placebo-controlled trial. Phytother. Res. 33 (5), 1374-1383. doi: 10.1002/ptr.6328

Ahmad Alobaidi, A. H. (2014). Effect of Nigella sativa and Allium sativum coadminstered with simvastatin in dyslipidemia patients: a prospective, randomized, double-blind trial. Antiinflamm. Antiallergy Agents Med. Chem. 13 (1), 68-74. doi: 10.2174/18715230113129990013

Akhter, F., Khan, M. S., Alatar, A. A., Faisal, M., and Ahmad, S. (2016). Antigenic role of the adaptive immune response to d-ribose glycated LDL in diabetes, atherosclerosis and diabetes atherosclerotic patients. Life Sci. 151, 139-146. doi: 10.1016/j.lfs.2016.02.013

Aksenov, D. V., Kaplun, V. V., Tertov, V. V., Sobenin, I. A., and Orekhov, A. N. (2007). Effect of plant extracts on trans-sialidase activity in human blood plasma. Bull. Exp. Biol. Med. 143, 46-50. doi: 10.1007/s10517-007-0013-2

Al Disi, S. S., Anwar, M. A., and Eid, A. H. (2016). Anti-hypertensive Herbs and their Mechanisms of Action: Part I. Front. Pharmacol. 19;6, 323. doi: 10.3389/ fphar.2015.00323

Alali, F. Q., El-Elimat, T., Khalid, L., Hudaib, R., Al-Shehabi, T. S., and Eid, A. H. (2017). Garlic for Cardiovascular Disease: Prevention or Treatment? Curr. Pharm. Des. 23 (7), 1028-1041. doi: 10.2174/1381612822666161010124530

Ali, M., Thomson, M., and Afzal, M. (2000). Garlic and onions: their effect on eicosanoid metabolism and its clinical relevance. Prostaglandins Leukot. Essent. Fatty Acids 62 (2), 55-73. doi: 10.1054/plef.1999.0124

Alipov, V. I., Sukhorukov, V. N., Karagodin, V. P., Grechko, A. V., and Orekhov, A. N. (2017). Chemical composition of circulating native and desialylated low density lipoprotein: what is the difference? Vessel Plus 1, 107-115. doi: 10.20517/2574-1209.2017.20

Allison, G. L., Lowe, G. M., and Rahman, K. (2012). Aged garlic extract inhibits platelet activation by increasing intracellular cAMP and reducing the interaction of GPIIb/IIIa receptor with fibrinogen. Life Sci. 91, 1275-1280. doi: 10.1016/j.lfs.2012.09.019

Al-Qattan, K. K., Khan, I., Alnaqeeb, M. A., and Ali, M. (2001). Thromboxane-B2, prostaglandin-E2 and hypertension in the rat 2-kidney 1-clip model: a possible mechanism of the garlic induced hypotension. Prostaglandins Leukot. Essent. Fatty Acids 64, 5-10. doi: 10.1054/plef.2000.0232

Al-Qattan, K. K., Thomson, M., Al-Mutawa'a, S., Al-Hajeri, D., Drobiova, H., and Ali, M. (2006). Nitric Oxide Mediates the Blood-Pressure Lowering Effect of Garlic in the Rat Two-Kidney, One-Clip Model of Hypertension. J. Nutr. 136, 774S-776S. doi: 10.1093/jn/136.3.774S

Anwar, M. A., Samaha, A. A., Ballan, S., Saleh, A. I., Iratni, R., and Eid, A. H. (2017). Salvia fruticosa Induces Vasorelaxation In Rat Isolated Thoracic Aorta: Role of the PI3K/Akt/eNOS/NO/cGMP Signaling Pathway. Sci. Rep. 7 (1), 686. doi: 10.1038/s41598-017-00790-9

Asdaq, S. M., and Inamdar, M. N. (2010). Potential of garlic and its active constituent, S-allyl cysteine, as antihypertensive and cardioprotective in presence of captopril. Phytomedicine 17, 1016-1026. doi: 10.1016/ j.phymed.2010.07.012

Ashraf, R., Khan, R. A., Ashraf, I., and Qureshi, A. A. (2013). Effects of Allium sativum (garlic) on systolic and diastolic blood pressure in patients with essential hypertension. Pak. J. Pharm. Sci. 26 (5), 859-863.

Bao, Y., Wang, L., Xu, Y., Yang, Y., Wang, L., Si, S., et al. (2012). Salvianolic acid B inhibits macrophage uptake of modified low density lipoprotein (mLDL) in a scavenger receptor CD36-dependent manner. Atherosclerosis 223, 152-159. doi: 10.1016/j.atherosclerosis.2012.05.006

Beckett, R. D., Schepers, S. M., and Gordon, S. K. (2015). Risk of new-onset diabetes associated with statin use. SAGE Open Med. 3, 2050312115605518. doi: 10.1177/2050312115605518

Bots, M. L., Evans, G. W., Tegeler, C. H., and Meijer, R. (2016). Carotid Intimamedia Thickness Measurements: Relations with Atherosclerosis, Risk of 
Cardiovascular Disease and Application in Randomized Controlled Trials. Chin. Med. J. (Engl.) 129 (2), 215-226. doi: 10.4103/0366-6999.173500

Castro, C., Lorenzo, A. G., González, A., and Cruzado, M. (2010). Garlic components inhibit angiotensin II-induced cell-cycle progression and migration: involvement of cell-cycle inhibitor p27Kip1 and mitogenactivated protein kinase. Mol. Nutr. Food Res. 54, 781-787. doi: 10.1002/ mnfr.200900108

Chan, Y. H., Lam, T. H., Lau, K. K., Yiu, K. H., Siu, C. W., Li, S. W., et al. (2011). Dietary intake of phytoestrogen is associated with increased circulating endothelial progenitor cells in patients with cardiovascular disease. Eur. J. Cardiovasc. Prev. Rehabil. 18, 360-368. doi: 10.1177/1741826710389385

Chang, Y. L., Chen, C. L., Kuo, C. L., Chen, B. C., and You, J. S. (2010). Glycyrrhetinic acid inhibits ICAM-1 expression via blocking JNK and NF-B pathways in TNF- $\alpha$-activated endothelial cells. Acta Pharmacol. Sin. 31, 546553. doi: 10.1038/aps.2010.34

Chang, X. X., Yan, H. M., Xu, Q., Xia, M. F., Bian, H., Zhu, T. F., et al. (2012). The effects of berberine on hyperhomocysteinemia and hyperlipidemia in rats fed with a long-term high-fat diet. Lipids Health Dis. 11, 86. doi: 10.1186/1476511X-11-86

Chao, P.-Y., Lin, K.-H., Chiu, C.-C., Yang, Y.-Y., Huang, M.-Y., and Yang, C.-M. (2013). Inhibitive Effects of Mulberry Leaf-Related Extracts on Cell Adhesion and Inflammatory Response in Human Aortic Endothelial Cells. Evid. Based Complement. Alternat. Med. 2013, 1-14. doi: 10.1155/2013/267217

Chen, W., Tang, F., Xie, B., Chen, S., Huang, H., and Liu, P. (2012). Amelioration of atherosclerosis by tanshinone IIA in hyperlipidemic rabbits through attenuation of oxidative stress. Eur. J. Pharmacol. 674, 359-364. doi: 10.1016/j.ejphar.2011.10.040

Chen, C., Cheng, G., Yang, X., Li, C., Shi, R., and Zhao, N. (2016). Tanshinol suppresses endothelial cells apoptosis in mice with atherosclerosis via lncRNA TUG1 up-regulating the expression of miR-26a. Am. J. Transl. Res. 8, 29812991.

Chi, L., Peng, L., Pan, N., Hu, X., and Zhang, Y. (2014). The anti-atherogenic effects of berberine on foam cell formation are mediated through the upregulation of sirtuin 1. Int. J. Mol. Med. 34, 1087-1093. doi: 10.3892/ ijmm.2014.1868

Chistiakov, D. A., Grechko, A. V., Myasoedova, V. A., Melnichenko, A. A., and Orekhov, A. N. (2018). The role of monocytosis and neutrophilia in atherosclerosis. J. Cell Mol. Med. 22, 1366-1382. doi: 10.1111/jcmm.13462

Choudhary, P. R., Jani, R. D., and Sharma, M. S. (2018). Effect of Raw Crushed Garlic (Allium sativum L.) on Components of Metabolic Syndrome. J. Diet. Suppl. 15 (4), 499-506. doi: 10.1080/19390211.2017.1358233

Chukwuma, C. I., Matsabisa, M. G., Ibrahim, M. A., Erukainure, O. L., Chabalala, M. H., and Islam, M. S. (2019). Medicinal plants with concomitant antidiabetic and anti-hypertensive effects as potential sources of dual acting therapies against diabetes and hypertension: A review. J. Ethnopharmacol. 235, 329-360. doi: 10.1016/j.jep.2019.02.024

Clifton-Bligh, P. B., Nery, M. L., Clifton-Bligh, R. J., Visvalingam, S., Fulcher, G. R., Byth, K., et al. (2015). Red clover isoflavones enriched with formononetin lower serum LDL cholesterol-a randomized, double-blind, placebo-controlled study. Eur. J. Clin. Nutr. 69 (1), 134-142. doi: 10.1038/ejcn.2014.207

Cook-Mills, J. M., Marchese, M. E., and Abdala-Valencia, H. (2011). Vascular Cell Adhesion Molecule-1 Expression and Signaling During Disease: Regulation by Reactive Oxygen Species and Antioxidants. Antioxid. Redox Signal. 15, 16071638. doi: 10.1089 /ars. 2010.3522

Davidson, M. H., Maki, K. C., Dicklin, M. R., Feinstein, S. B., Witchger, M., Bell, M., et al. (2009). Effects of consumption of pomegranate juice on carotid intima-media thickness in men and women at moderate risk for coronary heart disease. Am. J. Cardiol. 104 (7), 936-942. doi: 10.1016/j.amjcard.2009.05.037

Davignon, J. (2012). Pleiotropic effects of pitavastatin. Br. J. Clin. Pharmacol. 73, 518-535. doi: 10.1111/j.1365-2125.2011.04139.x

Di Vito, C., Bertoni, A., Nalin, M., Sampietro, S., Zanfa, M., and Sinigaglia, F. (2012). The phytoestrogen 8-prenylnaringenin inhibits agonist-dependent activation of human platelets. Biochim. Biophys. Acta 1820 (11), 1724-1733. doi: 10.1016/j.bbagen.2012.06.018

Du, L., Li, J., Zhang, X., Wang, L., and Zhang, W. (2018). Pomegranate peel polyphenols inhibits inflammation in LPS-induced RAW264.7 macrophages via the suppression of MAPKs activation. J. Funct. Foods 43, 62-69. doi: 10.1016/j.jff.2018.01.028
Fan, X., Wang, J., Hou, J., Lin, C., Bensoussan, A., Chang, D., et al. (2015). Berberine alleviates ox-LDL induced inflammatory factors by up-regulation of autophagy via AMPK/mTOR signaling pathway. J. Transl. Med. 13, 92. doi: 10.1186/s12967-015-0450-z

Fatkhullina, A. R., Peshkova, I. O., and Koltsova, E. K. (2016). The role of cytokines in the development of atherosclerosis. Biochemistry (Mosc.) 81 (11), 1358-1370. doi: 10.1134/S0006297916110134

Fogelman, Y., Gaitini, D., and Carmeli, E. (2016). Antiatherosclerotic effects of licorice extract supplementation on hypercholesterolemic patients: decreased CIMT, reduced plasma lipid levels, and decreased blood pressure. Food Nutr. Res. 60, 30830. doi: 10.3402/fnr.v60.30830

Franke, A. A., Custer, L. J., Wang, W., and Shi, C. Y. (1998). HPLC analysis of isoflavonoids and other phenolic agents from foods and from human fluids. Proc. Soc. Exp. Biol. Med. 217, 263-273. doi: 10.3181/00379727-217-44231

Fredman, G., and Spite, M. (2013). Recent advances in the role of immunity in atherosclerosis. Circ. Res. 113, el11-e114. doi: 10.1161/CIRCRESAHA.113.302986

Frostegard, J. (2013). Immunity, atherosclerosis and cardiovascular disease. $B M C$ Med. 11, 117. doi: 10.1186/1741-7015-11-117

Guo, J., Wang, L., Wang, L., Qian, S., Zhang, D., Fang, J., et al. (2016). Berberine Protects Human Umbilical Vein Endothelial Cells against LPS-Induced Apoptosis by Blocking JNK-Mediated Signaling. Evid. Based Complement. Alternat. Med. 2016, 6983956. doi: 10.1155/2016/6983956

Ha, A. W., Ying, T., and Kim, W. K. (2015). The effects of black garlic (Allium satvium) extracts on lipid metabolism in rats fed a high fat diet. Nutr. Res. Pract. 9, 30-36. doi: 10.4162/nrp.2015.9.1.30

Hao, P. P., Jiang, F., Chen, Y. G., Yang, J., Zhang, K., Zhang, M. X., et al. (2015). Evidence for traditional Chinese medication to treat cardiovascular disease. Nat. Rev. Cardiol. 12, p374. doi: 10.1038/nrcardio.2014.177-c2

Hao, P., Jiang, F., Cheng, J., Ma, L., Zhang, Y., and Zhao, Y. (2017). Traditional Chinese Medicine for Cardiovascular Disease: Evidence and Potential Mechanisms. J. Am. Coll. Cardiol. 69, 2952-2966. doi: 10.1016/ j.jacc.2017.04.041

Harzallah, A., Hammami, M., Kępczyńska, M. A., Hislop, D. C., Arch, J. R. S., Cawthorne, M. A., et al. (2016). Comparison of potential preventive effects of pomegranate flower, peel and seed oil on insulin resistance and inflammation in high-fat and high-sucrose diet-induced obesity mice model. Arch. Physiol. Biochem. 122, 75-87. doi: 10.3109/13813455.2016.1148053

Higashikawa, F., Noda, M., Awaya, T., Ushijima, M., and Sugiyama, M. (2012). Reduction of serum lipids by the intake of the extract of garlic fermented with Monascus pilosus: a randomized, double-blind, placebo-controlled clinical trial. Clin. Nutr. 31 (2), 261-266. doi: 10.1016/j.clnu.2011.10.008

Hodis, H. N., MacK, W. J., Kono, N., Azen, S. P., Shoupe, D., Hwang-Levine, J., et al. (2011). Isoflavone soy protein supplementation and atherosclerosis progression in healthy postmenopausal women: a randomized controlled trial. Stroke 42, 3168-3175. doi: 10.1161/STROKEAHA.111.620831

Huang, Z. S., Zeng, C. L., Zhu, L. J., Jiang, L., Li, N., and Hu, H. (2010). Salvianolic acid A inhibits platelet activation and arterial thrombosis via inhibition of phosphoinositide 3-kinase. J. Thromb. Haemost. 8, 1383-1393. doi: 10.1111/ j.1538-7836.2010.03859.x

Huang, Z., Wang, L., Meng, S., Wang, Y., Chen, T., and Wang, C. (2011). Berberine reduces both MMP-9 and EMMPRIN expression through prevention of $\mathrm{p} 38$ pathway activation in PMA-induced macrophages. Int. J. Cardiol. 146, 153-158. doi: 10.1016/j.ijcard.2009.06.023

Huang, Z., Meng, S., Wang, L., Wang, Y., Chen, T., and Wang, C. (2012). Suppression of oxLDL-induced MMP-9 and EMMPRIN expression by berberine via inhibition of NF- $\mathrm{\kappa B}$ activation in human THP-1 macrophages. Anat. Rec. 295, 78-86. doi: 10.1002/ar.21489

Huang, Y. H., Chen, S. T., Liu, F. H., Hsieh, S. H., Lin, C. H., Liou, M. J., et al. (2019). The efficacy and safety of concentrated herbal extract granules, YH1, as an add-on medication in poorly controlled type 2 diabetes: A randomized, double-blind, placebo-controlled pilot trial. PloS One 14 (8), e0221199. doi: 10.1371/journal.pone.0221199

Hwang, J. M., Cho, J. S., Kim, T. H., and Lee, Y. I. (2010). Ellagic acid protects hepatocytes from damage by inhibiting mitochondrial production of reactive oxygen species. BioMed. Pharmacother. 64, 264-270. doi: 10.1016/ j.biopha.2009.06.013

Joe, Y., Zheng, M., Kim, H. J., Kim, S., Uddin, M. J., Park, C., et al. (2012). Salvianolic acid B exerts vasoprotective effects through the modulation of heme 
oxygenase-1 and arginase activities. J. Pharmacol. Exp. Ther. 341, 850-858. doi: 10.1124/jpet.111.190736

Jong, S. K., Yeo, D. Y., Mi, H. H., Han, S. B., Lee, K., Ki, H. L., et al. (2006). Glabridin suppresses intercellular adhesion molecule-1 expression in tumor necrosis factor- $\alpha$-stimulated human umbilical vein endothelial cells by blocking sphingosine kinase pathway: Implications of Akt, extracellular signal-regulated kinase, and nuclear factor- $\mathrm{KB} /$ Rel signaling pathways. Mol. Pharmacol. 69, 941-949. doi: 10.1124/mol.105.017442

Jung, E. S., Park, S. H., Choi, E. K., Ryu, B. H., Park, B. H., Kim, D. S., et al. (2014). Reduction of blood lipid parameters by a 12-wk supplementation of aged black garlic: a randomized controlled trial. Nutrition 30 (9), 1034-1039. doi: 10.1016/ j.nut.2014.02.014

Kang, M. R., Park, K. H., Oh, S. J., Yun, J., Lee, C. W., Lee, M. Y., et al. (2015). Cardiovascular protective effect of glabridin: implications in LDL oxidation and inflammation. Int. Immunopharmacol. 29, 914-918. doi: 10.1016/ j.intimp.2015.10.020

Karagodin, V. P., Sobenin, I. A., and Orekhov, A. N. (2016a). Antiatherosclerotic and Cardioprotective Effects of Time-Released Garlic Powder Pills. Curr. Pharm. Des. 22, 196-213. doi: 10.2174/1381612822666151112153351

Karagodin, V. P., Sobenin, I. A., and Orekhov, A. N. (2016b). Antiatherosclerotic and Cardioprotective Effects of Time-Released Garlic Powder Pills. Curr. Pharm. Des. 22 (2), 196-213. doi: 10.2174/1381612822666151112153351

Katakami, N., Matsuoka, T. A., and Shimomura, I. (2019). Clinical utility of carotid ultrasonography: application for the management of patients with diabetes. J. Diabetes Invest. 10 (4), 883-898. doi: 10.1111/jdi.13042

Kim, D.-S., Ji, H. D., Rhee, M. H., Sung, Y.-Y., Yang, W.-K., Kim, S. H., et al. (2014). Antiplatelet Activity of Morus alba Leaves Extract, Mediated via Inhibiting Granule Secretion and Blocking the Phosphorylation of Extracellular-Signal-Regulated Kinase and Akt. Evid. Based Complement. Alternat. Med. 2014, 1-11. doi: 10.1155/2014/639548

Kim, J. S., Kim, J. H., Palaniyandi, S. A., Lee, C. C., You, J. W., Yang, H., et al. (2019). Yak-Kong Soybean (Glycine max) Fermented by a Novel Pediococcus pentosaceus Inhibits the Oxidative Stress-Induced Monocyte-Endothelial Cell Adhesion. Nutrients 11 (6), 1380. doi: 10.3390/nu11061380

Kirichenko, T. V., Sobenin, I. A., Nikolic, D., Rizzo, M., and Orekhov, A. N. (2016). Anti-cytokine therapy for prevention of atherosclerosis. Phytomedicine 23, 1198-1210. doi: 10.1016/j.phymed.2015.12.002

Kirichenko, T. V., Myasoedova, V. A., Orekhova, V. A., Ravani, A. L., Nikitina, N. A., Grechko, A. V., et al. (2017). Phytoestrogen-Rich Natural Preparation for Treatment of Climacteric Syndrome and Atherosclerosis Prevention in Perimenopausal Women. Phytother. Res. 31, 1209-1214. doi: 10.1002/ptr.5841

Kocaadam, B., and Şanlier, N. (2017). Curcumin, an active component of turmeric (Curcuma longa), and its effects on health. Crit. Rev. Food Sci. Nutr. 57, 28892895. doi: 10.1080/10408398.2015.1077195

Koch, M., and Zernecke, A. (2014). The hemostatic system as a regulator of inflammation in atherosclerosis. IUBMB Life. 66, 735-744. doi: 10.1002/iub.1333

Kong, W., Wei, J., Abidi, P., Lin, M., Inaba, S., Li, C., et al. (2004). Berberine is a novel cholesterol-lowering drug working through a unique mechanism distinct from statins. Nat. Med. 10, 1344-1351. doi: 10.1038/nm1135

Koon, C. M., Woo, K. S., Leung, P. C., and Fung, K. P. (2011). Salviae Miltiorrhizae Radix and Puerariae Lobatae Radix herbal formula mediates antiatherosclerosis by modulating key atherogenic events both in vascular smooth muscle cells and endothelial cells. J. Ethnopharmacol. 138, 175-183. doi: $10.1016 /$ j.jep.2011.08.073

Koon, C. M., Ko, C. H., Sun, X. X., Hoi, S. W., Tam, J. C., Cheung, D. W., et al. (2013). Gene expression profiling on the molecular action of danshen-gegen formula in a randomized placebo-controlled trial of postmenopausal women with hypercholesterolemia. Evid. Based Complement. Alternat. Med. 2013, 703705. doi: 10.1155/2013/703705

Koscielny, J., Klüssendorf, D., Latza, R., Schmitt, R., Radtke, H., Siegel, G., et al. (1999). The antiatherosclerotic effect of Allium sativum. Atherosclerosis 144 (1), 237-249. doi: 10.1016/S0021-9150(99)00060-X

Kou, J. Y., Li, Y., Zhong, Z. Y., Jiang, Y. Q., Li, X. S., Han, X. B., et al. (2017). Berberine-sonodynamic therapy induces autophagy and lipid unloading in macrophage. Cell Death Dis. 8 (1), e2558. doi: 10.1038/cddis.2016.354

Kwok, T., Leung, P. C., Lam, C., Ho, S., Wong, C. K., Cheng, K. F., et al. (2014). A randomized placebo controlled trial of an innovative herbal formula in the prevention of atherosclerosis in postmenopausal women with borderline hypercholesterolemia. Complement. Ther. Med. 22 (3), 473-480. doi: 10.1016/j.ctim.2014.03.010

Kwon, H. M., Choi, Y. J., Choi, J. S., Kang, S. W., Bae, J. Y., Kang, I. J., et al. (2007), Blockade of cytokine-induced endothelial cell adhesion molecule expression by licorice isoliquiritigenin through NF-KB signal disruption. Exp. Biol. Med. 232, 235-245.

Lee, T.-S., Pan, C.-C., Peng, C.-C., Kou, Y. R., Chen, C.-Y., Ching, L.-C., et al. (2010). Anti-atherogenic effect of berberine on LXR $\alpha$-ABCA1-dependent cholesterol efflux in macrophages. J. Cell Biochem. 111, 104-110. doi: $10.1002 / j c b .22667$

Li, B., Li, W., Li, X., and Zhou, H. (2017). Inflammation: A Novel Therapeutic Target/Direction in Atherosclerosis. Curr. Pharm. Des. 23, 1216-1227. doi: $10.2174 / 1381612822666161230142931$

Libby, P., Ridker, P. M., and Hansson, G. K. (2011). Progress and challenges in translating the biology of atherosclerosis. Nature 473, 317-325. doi: 10.1038/ nature 10146

Lin, R., Wang, W. R., Liu, J. T., Yang, G. D., and Han, C. J. (2006). Protective effect of tanshinone IIA on human umbilical vein endothelial cell injured by hydrogen peroxide and its mechanism. J. Ethnopharmacol. 108, 217-222. doi: 10.1016/j.jep.2006.05.004

Lin, X. L., Liu, M. H., Hu, H. J., Feng, H. R., Fan, X. J., Zou, W. W., et al. (2015). Curcumin Enhanced Cholesterol Efflux by Upregulating ABCA1 Expression Through AMPK-SIRT1-LXR $\alpha$ Signaling in THP-1 Macrophage-Derived Foam Cells. DNA Cell Biol. 34, 561-572. doi: 10.1089/dna.2015.2866

Liu, L. T., Zheng, G. J., Zhang, W. G., Guo, G., and Wu, M. (2014). Clinical study on treatment of carotid atherosclerosis with extraction of polygoni cuspidati rhizoma et radix and crataegi fructus: a randomized controlled trial. Zhongguo Zhong Yao Za Zhi 39 (6), 1115-1119.

Liu, Z., Xu, S., Huang, X., Wang, J., Gao, S., Li, H., et al. (2015). Cryptotanshinone, an orally bioactive herbal compound from Danshen, attenuates atherosclerosis in apolipoprotein E-deficient mice: Role of lectin-like oxidized LDL receptor-1 (LOX-1). Br. J. Pharmacol. 172, 5661-5675. doi: 10.1111/bph.13068

Lopes-Virella, M. F., and Virella, G. (2013). Pathogenic role of modified LDL antibodies and immune complexes in atherosclerosis. J. Atheroscl. Thromb. 20, 743-754. doi: 10.5551/jat.19281

Maaliki, D., Shaito, A. A., Pintus, G., El-Yazbi, A., and Eid, A. H. (2019). Flavonoids in hypertension: a brief review of the underlying mechanisms. Curr. Opin. Pharmacol. 45, 57-65. doi: 10.1016/j.coph.2019.04.014

Mahdavi-Roshan, M., Zahedmehr, A., Mohammad-Zadeh, A., Sanati, H. R., Shakerian, F., Firouzi, A., et al. (2013). Effect of garlic powder tablet on carotid intima-media thickness in patients with coronary artery disease: a preliminary randomized controlled trial. Nutr. Health 22 (2), 143-155. doi: $10.1177 / 0260106014563446$

Mahdavi-Roshan, M., Nasrollahzadeh, J., Mohammad Zadeh, A., and Zahedmehr, A. (2016). Does Garlic Supplementation Control Blood Pressure in Patients with Severe Coronary Artery Disease? A Clinical Trial Study. Iran Red Crescent Med. J. 18 (11), e23871. doi: 10.5812/ircmi.23871

Mandal, A., Bhatia, D., and Bishayee, A. (2017). Anti-Inflammatory Mechanism Involved in Pomegranate-Mediated Prevention of Breast Cancer: the Role of NF- $\mathrm{KB}$ and Nrf2 Signaling Pathways. Nutrients 9, 436. doi: 10.3390/nu9050436

Mansour, M. H., Al-Qattan, K., Thomson, M., and Ali, M. (2013). Garlic (Allium sativum) down-regulates the expression of angiotensin II AT1 receptor in adrenal and renal tissues of streptozotocin-induced diabetic rats. Inflammopharmacology 21, 147-159. doi: 10.1007/s10787-012-0139-3

Morihara, N., and Hino, A. (2017). Aged garlic extract suppresses platelet aggregation by changing the functional property of platelets. J. Nat. Med. 71 , 249-256. doi: 10.1007/s11418-016-1055-4

Myasoedova, V. A., Kirichenko, T. V., Melnichenko, A. A., Orekhova, V. A., Ravani, A., Poggio, P., et al. (2016). Anti-atherosclerotic effects of a phytoestrogen-rich herbal preparation in postmenopausal women. Int. J. Mol. Sci. 17 (8), 1318. doi: 10.3390/ijms17081318

Nikifirov, N. G., Zakiev, E. R., Elizova, N. V., Sukhorukov, V. N., and Orekhov, A. N. (2017). Multiple-modified low-density lipoprotein as atherogenic factor of patients' blood: Development of therapeutic approaches to reduce blood atherogenicity(Review). Curr. Pharm. Des. 23, 932-936. doi: 10.2174/ 1381612823666170124112918

Nikitina, N. A., Sobenin, I. A., Myasoedova, V. A., Korennaya, V. V., Mel'nichenko, A. A., Khalilov, E. M., et al. (2006). Antiatherogenic effect of 
grape flavonoids in an ex vivo model. Bull. Exp. Biol. Med. 141 (6), 712-715. doi: 10.1007/s10517-006-0260-7

Oesterle, A., Laufs, U., and Liao, J. K. (2017). Pleiotropic Effects of Statins on the Cardiovascular System [published correction appears in Circ Res. Circ. Res. 120, 229-243. doi: 10.1161/CIRCRESAHA.116.308537

Orekhov, A. N., and Ivanova, E. A. (2017). Introduction of the special issue Atherosclerosis and Related. Dis. Vessel Plus 1, 163-165. doi: 10.20517/25741209.2017.33

Orekhov, A. N., Sobenin, I. A., Korneev, N. V., Kirichenko, T. V., Myasoedova, V. A., Melnichenko, A. A., et al. (2013). Anti-atherosclerotic therapy based on botanicals. Recent Pat. Cardiovasc. Drug Discov. 8 (1), 56-66. doi: 10.2174/ 18722083113079990008

Orekhov, A. N., Sobenin, I. A., Revin, V. V., and Bobryshev, Y. V. (2015). Development of Antiatherosclerotic Drugs on the basis of Natural Products Using Cell Model Approach. Oxid. Med. Cell Longev. 2015, 463797. doi: $10.1155 / 2015 / 463797$

Oseni, T., Patel, R., Pyle, J., and Jordan, V. C. (2008). Selective estrogen receptor modulators and phytoestrogens. Planta Med. 74, 1656-1665. doi: 10.1055/s0028-1088304

Panahi, Y., Khalili, N., Sahebi, E., Namazi, S., Simental-Mendía, L. E., Majeed, M., et al. (2018). Effects of Curcuminoids Plus Piperine on Glycemic, Hepatic and Inflammatory Biomarkers in Patients with Type 2 Diabetes Mellitus: A Randomized Double-Blind Placebo-Controlled Trial. Drug Res. (Stuttg.) 68 (7), 403-409. doi: 10.1055/s-0044-101752

Park, S. H., Kang, J. S., Yoon, Y. D., Lee, K., Kim, K. J., Lee, K. H., et al. (2010). Glabridin inhibits lipopolysaccharide-induced activation of a microglial cell line, BV-2, by blocking NF-KB and AP-1. Phytother Res. 1, S29-S34. doi: $10.1002 /$ ptr.2872

Pogosova, N. V., Oganov, R. G., Boytsov, S. A., Ausheva, A. K., Sokolova, O. Y., Kursakov, A. A., et al (2017). Efficiency of primary prevention for diseases caused by atherosclerosis in patients at high cardiovascular risk in Russia and other European countries (Part 2). Kardiologiia 57, (83) 5-16. doi: 10.18087/cardio.2412

Pirillo, A., Norata, G. D., and Catapano, A. L. (2013). LOX-1, OxLDL, and atherosclerosis. Mediators Inflamm. 2013, 152786. doi: 10.1155/2013/152786

Qiao, L., and Chen, W. (2018). Atheroprotective effects and molecular targets of bioactive compounds from traditional Chinese medicine. Pharmacol. Res. 135, 212-229. doi: 10.1016/j.phrs.2018.07.012

Rahman, K., Lowe, G. M., and Smith, S. (2016). Aged Garlic Extract Inhibits Human Platelet Aggregation by Altering Intracellular Signaling and Platelet Shape Change. J. Nutr. 146, 410S-415S. doi: 10.3945/jn.114.202408

Rahman, K. (2007). Effects of garlic on platelet biochemistry and physiology. Mol. Nutr. Food Res. 51 (11), 1335-1344. doi: 10.1002/mnfr.200700058

Rai, S. K., Sharma, M., and Tiwari, M. (2009). Inhibitory effect of novel diallyldisulfide analogs on HMG-CoA reductase expression in hypercholesterolemic rats: CREB as a potential upstream target. Life Sci. 85 (5-6), 211-219. doi: 10.1016/j.lfs.2009.05.020

Ramji, D. P., and Davies, T. S. (2015). Cytokines in atherosclerosis: key players in all stages of disease and promising therapeutic targets. Cytokine Growth Factor Rev. 26 (6), 673-685. doi: 10.1016/j.cytogfr.2015.04.003

Ried, K., and Fakler, P. (2014). Potential of garlic (Allium sativum) in lowering high blood pressure: Mechanisms of action and clinical relevance. Integr. Blood Press. Control 7, 71-82. doi: 10.2147/IBPC.S51434

Rosenblat, M., Belinky, P., Vaya, J., Levy, R., Hayek, T., Coleman, R., et al. (1999). Macrophage enrichment with the isoflavan glabridin inhibits NADPH oxidaseinduced cell-mediated oxidation of low density lipoprotein. A possible role for protein kinase C. J. Biol. Chem. 274, 13790-13799. doi: 10.1074/jbc.274.20.13790

Saadati, S., Sadeghi, A., Mansour, A., Yari, Z., Poustchi, H., Hedayati, M., et al. (2019). Curcumin and inflammation in non-alcoholic fatty liver disease: a randomized, placebo controlled clinical trial. BMC Gastroenterol. 19 (1), 133. doi: 10.1186/s12876-019-1055-4

Sathyapalan, T., Aye, M., Rigby, A. S., Thatcher, N. J., Dargham, S. R., Kilpatrick, E. S., et al. (2018). Soy isoflavones improve cardiovascular disease risk markers in women during the early menopause. Nutr. Metab. Cardiovasc. Dis. 28 (7), 691-697. doi: 10.1016/j.numecd.2018.03.007

Sedaghat, A., Shahbazian, H., Rezazadeh, A., Haidari, F., Jahanshahi, A., Mahmoud Latifi, S., et al. (2019). The effect of soy nut on serum total antioxidant, endothelial function and cardiovascular risk factors in patients with type 2 diabetes. Diabetes Metab. Syndr. 13 (2), 1387-1391. doi: 10.1016/ j.dsx.2019.01.057

Sedighi, M., Bahmani, M., Asgary, S., Beyranvand, F., and Rafieian-Kopaei, M. (2017). A review of plant-based compounds and medicinal plants effective on atherosclerosis. J. Res. Med. Sci. 22, 30. doi: 10.4103/1735-1995.202151

Shouk, R., Abdou, A., Shetty, K., Sarkar, D., and Eid, A. H. (2014). Mechanisms underlying the antihypertensive effects of garlic bioactives. Nutr. Res. 34 (2), 106-115. doi: 10.1016/j.nutres.2013.12.005

Sobenin, I. A., Andrianova, I. V., Demidova, O. N., Gorchakova, T. V., and Orekhov, A. N. (2008a). Lipid-lowering Effects of Time-Released Garlic Power Tablets in Double-Blinded Placebo-Controlled Randomized Study. J. Atheroscler. Thromb. 15 (6), 334-338. doi: 10.5551/jat.E550

Sobenin, I. A., Nedosugova, L. V., Filatova, L. V., Balabolkin, M. I., Gorchakova, T. V., and Orekhov, A. N. (2008b). Metabolic effects of time-released garlic powder tablets in type 2 diabetes mellitus: the results of double-blinded placebo-controlled study. Acta Diabetol. 45 (1), 1-6. doi: 10.1007/s00592-007-0011-x

Sobenin, I. A., Andrianova, I. V., Fomchenkov, I. V., Gorchakova, T. V., and Orekhov, A. N. (2009). Time-released garlic powder tablets lower systolic and diastolic blood pressure in men with mild and moderate arterial hypertension. Hypertens. Res. 32 (6), 433-437. doi: 10.1038/hr.2009.36

Sobenin, I. A., Andrianova, I. V., Lakunin, K. Y., Karagodin, V. P., Bobryshev, Y. V., and Orekhov, A. N. (2016a). Anti-atherosclerotic effects of garlic preparation in freeze injury model of atherosclerosis in cholesterol-fed rabbits. Phytomedicine 23, 12351239. doi: 10.1016/j.phymed.2015.10.014

Sobenin, I. A., Myasoedova, V. A., and Orekhov, A. N. (2016b). Phytoestrogen-Rich Dietary Supplements in Anti-Atherosclerotic Therapy in Postmenopausal Women. Curr. Pharm. Des. 22 (2), 152-163. doi: 10.2174/1381612822666151112150520

Sobenin, I. A., Galitsyna, E. V., Grechko, A. V., and Orekhov, A. N. (2017). Small dense and desialylated low density lipoprotein in diabetic patients. Vessel Plus 1, 29-37. doi: 10.20517/2574-1209.2016.12

Stroes, E. S., Thompson, P. D., Corsini, A., Vladutiu, G. D., Raal, F. J., Ray, K. K., et al. (2015). Statin-associated muscle symptoms: impact on statin therapyEuropean Atherosclerosis Society Consensus Panel Statement on Assessment, Aetiology and Management. Eur. Heart J. 36 (17), 1012-1022. doi: 10.1093/ eurheartj/ehv043

Tabas, I., and Lichtman, A. H. (2017). Monocyte-macrophages and T cells in atherosclerosis. Immunity 47, 621-634. doi: 10.1016/j.immuni.2017.09.008

Tariq, S., Imran, M., Mushtaq, Z., and Asghar, N. (2016). Phytopreventive antihypercholesterolmic and antilipidemic perspectives of zedoary (Curcuma Zedoaria Roscoe.) herbal tea. Lipids Health Dis. 15, 39. doi: 10.1186/s12944016-0210-y

Tian, J., Gu, X., Sun, Y., Ban, X., Xiao, Y., Hu, S., et al. (2012). Effect of statin therapy on the progression of coronary atherosclerosis. BMC Cardiovasc. Disord. 12, 70. doi: 10.1186/1471-2261-12-70

Venkataiah, V., Vickram, Thirumalarao, K. R., Raiker, V. G., and Puttaswamy, S. H. (2016). Effects of diaceto-dipropyl-disulphide on plasma sialic acid and renal tissue thiol levels in alloxan diabetic rats. J. Clin. Diagn. Res. 10, BF06-BF08. doi: 10.7860/ JCDR/2016/19241.8058

Vilahur, G., and Badimon, L. (2013). Antiplatelet properties of natural products. Vascul. Pharmacol. 59 (3-4), 67-75. doi: 10.1016/j.vph.2013.08.002

Villa, P., Amar, I. D., Bottoni, C., Cipolla, C., Dinoi, G., Moruzzi, M. C., et al. (2017). The impact of combined nutraceutical supplementation on quality of life and metabolic changes during the menopausal transition: a pilot randomized trial. Arch. Gynecol. Obstet. 296 (4), 791-801. doi: 10.1007/ s00404-017-4491-9

Witztum, J. L., and Lichtman, A. H. (2014). The influence of innate and adaptive immune responses on atherosclerosis. Annu. Rev. Pathol. 9, 73-102. doi: 10.1146/annurev-pathol-020712-163936

Woo, K. S., Yip, T. W., Chook, P., Kwong, S. K., Szeto, C. C., Li, J. K., et al. (2013). Cardiovascular Protective Effects of Adjunctive Alternative Medicine (Salvia miltiorrhiza and Pueraria lobata) in High-Risk Hypertension. Evid. Based Complement. Alternat. Med. 2013, 132912. doi: 10.1155/2013/132912

Xu, C., Mathews, A. E., Rodrigues, C., Eudy, B. J., Rowe, C. A., O'Donoughue, A., et al. (2018). Aged garlic extract supplementation modifies inflammation and immunity of adults with obesity: A randomized, double-blind, placebocontrolled clinical trial. Clin. Nutr. ESPEN 24, 148-155. doi: 10.1016/ j.clnesp.2017.11.010 
Yang, T. L., Lin, F. Y., Chen, Y. H., Chiu, J. J., Shiao, M. S., Tsai, C. S., et al. (2011). Salvianolic acid B inhibits low-density lipoprotein oxidation and neointimal hyperplasia in endothelium-denuded hypercholesterolaemic rabbits. J. Sci. Food Agric. 91, 134-141. doi: 10.1002/jsfa.4163

Yang, J. X., Pan, Y. Y., Ge, J. H., Chen, B., Mao, W., Qiu, Y. G., et al. (2016). Tanshinone II A Attenuates TNF- $\alpha$-Induced Expression of VCAM-1 and ICAM-1 in Endothelial Progenitor Cells by Blocking Activation of NF- $\mathrm{BB}$. Cell Physiol. Biochem. 40, 195-206. doi: 10.1159/000452537

Yang, Y., Li, X., Peng, L., An, L., Sun, N., Hu, X., et al. (2018). Tanshindiol C inhibits oxidized low-density lipoprotein induced macrophage foam cell formation via a peroxiredoxin 1 dependent pathway. Biochim. Biophys. Acta 1864, 882-890. doi: 10.1016/j.bbadis.2017.12.033

Yu, X., Xu, L., Zhou, Q., Wu, S., Tian, J., Piao, C., et al. (2018). The Efficacy and Safety of the Chinese Herbal Formula, JTTZ, for the Treatment of Type 2 Diabetes with Obesity and Hyperlipidemia: A Multicenter Randomized, Positive-Controlled, Open-Label Clinical Trial. Int. J. Endocrinol. 2018, 9519231. doi: 10.1155/2018/9519231

Zeb, F., Safdar, M., Fatima, S., Khan, S., Alam, S., Muhammad, M., et al. (2018). Supplementation of garlic and coriander seed powder: Impact on body mass index, lipid profile and blood pressure of hyperlipidemic patients. Pak. J. Pharm. Sci. 31 (5), 1935-1941.

Zhang, B., Chen, Y. M., Huang, L. L., Zhou, X. X., Chen, C. G., Ye, Y. B., et al. (2008). Greater habitual soyfood consumption is associated with decreased carotid intimamedia thickness and better plasma lipids in Chinese middle-aged adults. Atherosclerosis 198 (2), 403-411. doi: 10.1016/j.atherosclerosis.2007.10.001

Zhao, J. F., Ching, L. C., Huang, Y. C., Chen, C. Y., Chiang, A. N., Kou, Y. R., et al. (2012). Molecular mechanism of curcumin on the suppression of cholesterol accumulation in macrophage foam cells and atherosclerosis. Mol. Nutr. Food Res. 56, 691-701. doi: 10.1002/mnfr.201100735

Zhao, W., Li, J., He, X., Lv, O., Cheng, Y., and Liu, R. (2014). In vitro steatosis hepatic cell model to compare the lipid-lowering effects of pomegranate peel polyphenols with several other plant polyphenols as well as its related cholesterol efflux mechanisms. Toxicol. Rep. 1, 945-954. doi: 10.1016/j.toxrep.2014.10.013

Zhao, W., Wu, C., and Chen, X. (2016). Cryptotanshinone inhibits oxidized LDLinduced adhesion molecule expression via ROS dependent NF- $\kappa \mathrm{B}$ pathways. Cell Adhes. Migr. 10, 248-258. doi: 10.1080/19336918.2015.1119361

Zhao, D., Tong, L., Zhang, L., Li, H., Wan, Y., and Zhang, T. (2016). Tanshinone II A stabilizes vulnerable plaques by suppressing RAGE signaling and NF- $\kappa \mathrm{B}$ activation in apolipoprotein-E-deficient mice. Mol. Med. Rep. 14, 4983-4990. doi: $10.3892 / \mathrm{mmr} .2016 .5916$

Zhao, S., Li, J., Wang, L., and Wu, X. (2016). Pomegranate peel polyphenols inhibit lipid accumulation and enhance cholesterol efflux in raw264.7 macrophages. Food Funct. 7, 3201-3210. doi: 10.1039/C6FO00347H

Zou, X., Yan, C., Shi, Y., Cao, K., Xu, J., Wang, X., et al. (2014). Mitochondrial Dysfunction in Obesity-Associated Nonalcoholic Fatty Liver Disease: The Protective Effects of Pomegranate with Its Active Component Punicalagin. Antioxid. Redox Signal. 21, 1557-1570. doi: 10.1089/ars.2013.5538

Conflict of Interest: GA was employed by GALLY International Biomedical Research LLC.

The remaining authors declare that the research was conducted in the absence of any commercial or financial relationships that could be construed as a potential conflict of interest.

Copyright (C) 2020 Kirichenko, Sukhorukov, Markin, Nikiforov, Liu, Sobenin, Tarasov, Orekhov and Aliev. This is an open-access article distributed under the terms of the Creative Commons Attribution License (CC BY). The use, distribution or reproduction in other forums is permitted, provided the original author(s) and the copyright owner(s) are credited and that the original publication in this journal is cited, in accordance with accepted academic practice. No use, distribution or reproduction is permitted which does not comply with these terms. 